Received 14 May 2020; accepted 3 January 2021.

Available online 9 January 2021

\title{
The Role of Urban Space Configuration in Maintaining Social Inclusion: A Comparison of Four Types of Neighborhoods in Greater Cairo Region-Egypt.
}

\section{Islam Ghonimi}

Associate Professor, Shubra Faculty of engineering, Benha University, Egypt. Islam.ghonimi@feng.bu.edu.eg

\begin{abstract}
Since the mid-twentieth century, the process of modernization caused an adaptation of westernized prototypes of residential neighborhoods in Greater Cairo Region. This evolution caused a relevant evolution of various prototypes of urban spaces, an evolution from traditional neighborhoods where street works as public space to new planned neighborhoods that concern quantitative provision of urban spaces as internal gardens inside superblock. The evolution was attractive for residents who escaped crowded traditional neighborhoods and claimed quantitative provision of urban spaces with well-designed landscape to enjoy better living conditions. Egyptian National Organization for Urban Harmony developed urban space design guidelines, to ensure quantitative and accessibility criteria. However, observation of urban spaces in new cities revealed failure to host residents and probably have negative impacts on social inclusion, cohesion, and participation. One reason behind that failure is the lack of empirical knowledge of expected impacts of design guidelines on social behavior. This research examines social sustainability of urban space configuration in four prototypes of neighborhoods, it also questions how socially sustainable are NOUH2010 design guidelines. The research depends on ethnographic observation and questionnaire survey that were conducted in selected neighborhoods. The paper reports, based on empirical findings, that modern urban spaces with quantitative provision of urban-spaces, hierarchical distribution, merged and central location, good accessibility and well-designed landscape are short sighted to achieve urban social sustainability; rather qualitative mixed use is most influential factor to encourage social inclusion, interaction and participation as by-product of movement and as subsidiary to other attractive activities.
\end{abstract}

KEYWORDS: Urban Space; Urban Social Sustainability; Social Cohesion; Social Inclusion; Social Participation; National Organization for Urban Harmony (NOUH).

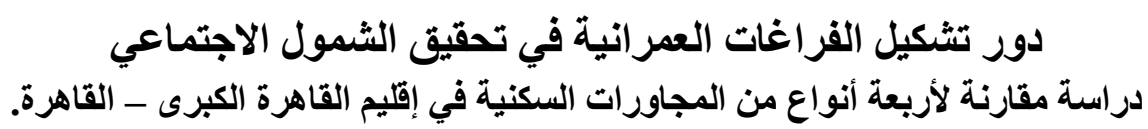

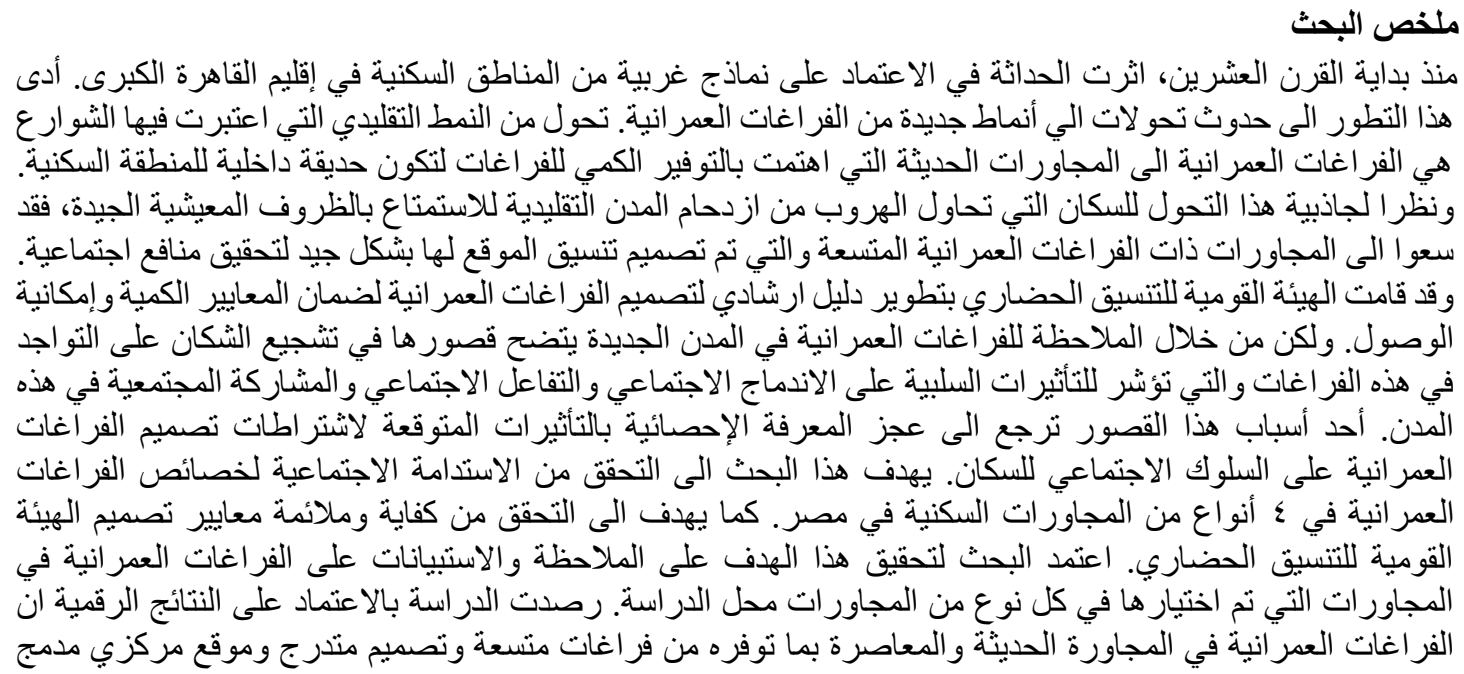




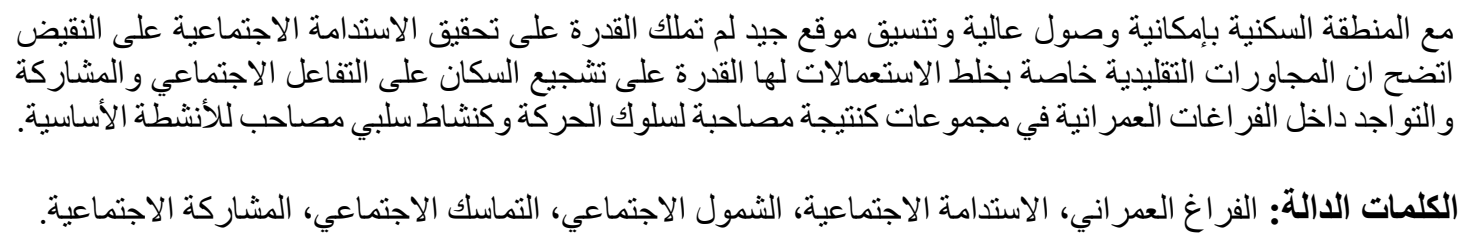

\section{INTRODUCTION}

Urban sociologists see the space as more than a physical space within which social processes operate; rather they found organization of space could enhance social inclusion, interaction, and participation and especially face to face co-presence. The evolution of residential neighborhoods in Greater Cairo Region witnessed a relevant evolution of various types of urban spaces. It was a transition from traditional neighborhoods where street works as public space to modern neighborhoods that concerns quantitative provision of urban spaces as internal gardens in superblock. Urban spaces in traditional neighborhoods are commonly faced with quantitative shortage. Streets become the only public spaces that can gather people where commercial uses are mixed with residential uses and gather pedestrians adjacent to car traffic. Accordingly, it becomes crowded accompanied with through traffic and unsafe for pedestrians and children. It becomes undesirable and uncomfortable for residents' social behavior and may cause social problems.

In order to face these negative impacts, planners developed different modern neighborhoods types, mostly adopted form the westernized world, hoping to give residents with enough urban spaces and green areas, in an aim to enhance social interaction and participation and provide safety and security by excluding through traffic from urban spaces, provide higher quantitative provision of urban spaces, and separate use. The evolution was attractive for residents who escape crowded traditional neighborhoods to enjoy better living conditions in modern neighborhoods. Furthermore, the Egyptian National Organization for Urban Harmony (NOUH) developed design guidelines of urban harmony for open green spaces, to ensure quantitative and accessibility criteria.

It is widely claimed in practice, that quantitative provision of urban spaces with welldesigned landscape will have positive social benefits for residents, and will foster social inclusion, and contribute to social cohesion and participation (Carmona, 2004). Further recent studies claimed that well-designed built environment encourages resident's inclusion to urban spaces and makes and make them feel more attached to their environment (Choguill, 2008; Chan and Lee, 2008). However, observation of current urban spaces in new cities revealed that it failed to host residents and activities and probably have negative impacts on social inclusion, cohesion, and participation. One reason behind that failure is the lack of empirical knowledge about the potential impacts of planning decisions and design guidelines for urban spaces within neighborhood and their expected impacts on social behavior.

Furthermore, a comparison of previous studies of urban social sustainability in term of geographical scale revealed a high focus of analysis on macro levels and neighborhood level, and a limited scientific research concern urban social sustainability in urban space scale (Mehan A. 2017). Among the limited studies in urban space scale contradicting results are recorded. Some scholars claimed that urban spaces of modern neighborhoods do little to enable social interaction and may not be designed to encourage social interaction (Calthorbe; Leyden 2003). On the other hand, other claims argue that social 
interaction record higher values when dwelling units are surrounding urban spaces (Karuppannan et. al. 2011; Farhadikhah et. al., 2020).

This makes the main concern of this research to target urban social sustainability in urban space levels. The research claims that the way urban spaces are designed inside neighborhoods can play a significant role in shaping residents' social behavior to enhance urban social sustainability. The research aims to identify how some urban space configurations can encourage social inclusion, cohesion, and participation than others, to develop guidelines to improve urban social sustainability in new cities.

The method used is inductive using descriptive and comparative analysis of different case studies, with different spatial configurations. It aims to test and compare the relation between the configuration of urban spaces in different types of neighborhoods and urban social sustainability indicators. The research depends on two interlocking stages: Firstly, literature review to introduce the variables of the research in terms of concepts, patterns, and measurable indices. Secondly, case studies in four categories of neighborhoods to test the relationship between the two variables. The field study goes through three steps: measuring social sustainability indicators using questionnaires and observation, measuring urban spaces configuration using spatial measures, and finally testing the validity of their relations.

\section{1- THE EVOLUTION OF NEIGHBORHOOD URBAN SPACES IN GCR}

The industrial revolution was the most influential change that bring urban planning to make deep turn from the organic city to the planned city. Through history, Cairo urban form witnessed a dramatic evolution of different residential prototypes as a manifestation of sociopolitical changes (Ghonimi, 2014). In the first half of the 20th Century, a process of modernization has taken place in Egypt that impacted the process of Cario's urban development to rest on adopting different westernized prototypes (Shalaby, 2003). One of such adopted models was Perry's neighborhood (1929), that developed inward oriented community to keep out the unwanted away from the neighborhood. Accordingly, he developed a self-contained neighborhood with inward oriented treed street network pattern, that separates non-residential uses out the community. Another adopted model by Clarence Stein and Henry Wright (1957) developed the modernist ideas of cluster housing and superblocks. They arranged the housing units in clusters on a series of cul-de-sacs surrounding an interior park and open space.

\subsection{Types of Neighborhoods in GCR}

The evolution of Cairo residential urban form reported different prototypes that are different in term of street network pattern, housing income pattern, and land use pattern (Ghonimi, 2017). Starting from the historical old Islamic Cairo, the informal development over agriculture land till the emergence of the process of modernization that left deep impacts on Cairo residential neighborhoods. Due to the deep changes in cultural, technical and transportation technology (Carmona et. al., 2010), the research excludes old Islamic Cairo and limit the analysis on a comparison between four prototypes: Informal early developed neighborhoods, early planned neighborhoods, new planned neighborhoods, and the contemporary planned neighborhood (Ibrahim, 2017; Ghonimi, 2017). 


\subsubsection{Early developed (Traditional) neighborhood: (Streets as public space)}

This prototype is developed over agriculture land at the early 20th Century, e.g., Abasiaa and Shoubra districts. It can be defined as informally grown development - in a natural/organic way - without proper designed plans, and as a reflection of informative intentions by the people and for the people, without the benefit of planner and without masterplans (Lynch, 1981; Jacobs, 1950; Carmona, 2002; Abu-Lughod, 1971). Its common characteristics are developed based on, first, compact urban form with high building density, small building lots without setbacks and tide streets. Secondly, high residential density. Thirdly, mixed uses that contain non-residential uses in ground floors mixed with residential uses in typical floors. Finally, a fine-grained grid street network pattern that consist of high number of egress points and high number of intersections that increase neighborhood permeability, connectivity, and accessibility with the surrounding area. This type of streets is considered as public spaces that not only function as links to connect different destinations, but also utilize multiple economic, ceremonial, political, cultural, and social functions. Urban spaces are defined by buildings across the streets.

\subsubsection{Early planned neighborhood: (urban space as fenced islands)}

This prototype is planned at the early and mid-20th century, e.g. Heliopolis is developed and planned by private developers in early 20th Century; Nasr city is developed and planned by the government in the mid-20th Century. These patterns are initiated and planed based on garden city style, with segregating land use patterns of pure residential clusters, with commercial area centered in the neighborhood; it is developed with modified rectilinear grid street with reduced number of entrances and intersections to partially exclude the surrounding, and based on small lots, mid-density housing development. It aimed to provide partial pedestrian safety by excluding through traffic and avoid crowdedness by excluding non-residential uses from residential area. Later, due to deregulation, these neighborhoods witnessed some transformation to soft mixed use in ground floor including shops, cafes, and other non-residential functions. In this type, the urban space is generated as an island between residential units. For security reasons it is separated with steel fences and access gates from residential units; where residents need to cross street and move to certain gates to access it.

\subsubsection{New planned neighborhood: (urban space as islands)}

This prototype is developed in the last four decades by government in settlements surrounding GCR e.g. New Cairo, and 6october. It is planned based on modern theories of residential district with segregated land use patterns of pure residential clusters, low density, and hierarchical street network pattern with the loop system, with all their services concentrated in the periphery of the neighborhood. This type of neighborhood aims to completely exclude through traffic and avoid crowdedness and exclude nonresidents. In this type, urban space is generated as an island between and in-front of residential units with internal gardens for residents. Urban spaces are partially separated from residential units by street; residents can cross the streets to access urban space.

\subsubsection{Contemporary private neighborhood: (urban spaces inside Superblock)}

This type is developed in the last two decades by private developers, at the latest extension of new settlements surrounding GCR. It is developed as simulation of suburban design based on pure residential clusters, with separate use services located 
at the periphery away from residential buildings. It is based on a hierarchical street network pattern, where houses are grouped around cul-de-sacs, served by collector streets on the perimeter to incorporate a spine of urban spaces in the middle of the superblock. Urban spaces are totally merged as internal gardens within the super block located at the backyard of residential buildings. Boundaries, fences, and streets are removed to foster resident's access to urban spaces.

\subsection{The Evolution of Urban space spatial configuration:}

Neighborhood urban spaces reported a relevant change as part of a larger change in neighborhood spatial layout and physical features. Based on numerous scientific literature review, table (1) represents the proudly deduced urban space configurations that can report the evolution between different neighborhood prototypes; such as quantitative provision, location, distribution, accessibility, and qualitative provision in terms of, primary and secondary function, and activities, and landscape design. Table (2) traces the spatial evolution of residential urban form in GCR and trace the relevant evolution of urban spaces configuration. Based on a spatial analysis of an analytical neighborhood model with area 30 acres and size $300 * 420 \mathrm{~m} 2$. It compares four types of urban space layout in term of distribution of streets network pattern, distribution of buildings block and urban space pattern which are arranged in each case according to the type of neighborhood it represents. The spatial analysis based on three types of analysis, first: streets patterns analysis (Southworth 2013), second: cross-section between street, buildings and urban space, and finally urban spaces patterns analysis.

Table 1. deduced urban space configuration based on literature review of previous studies

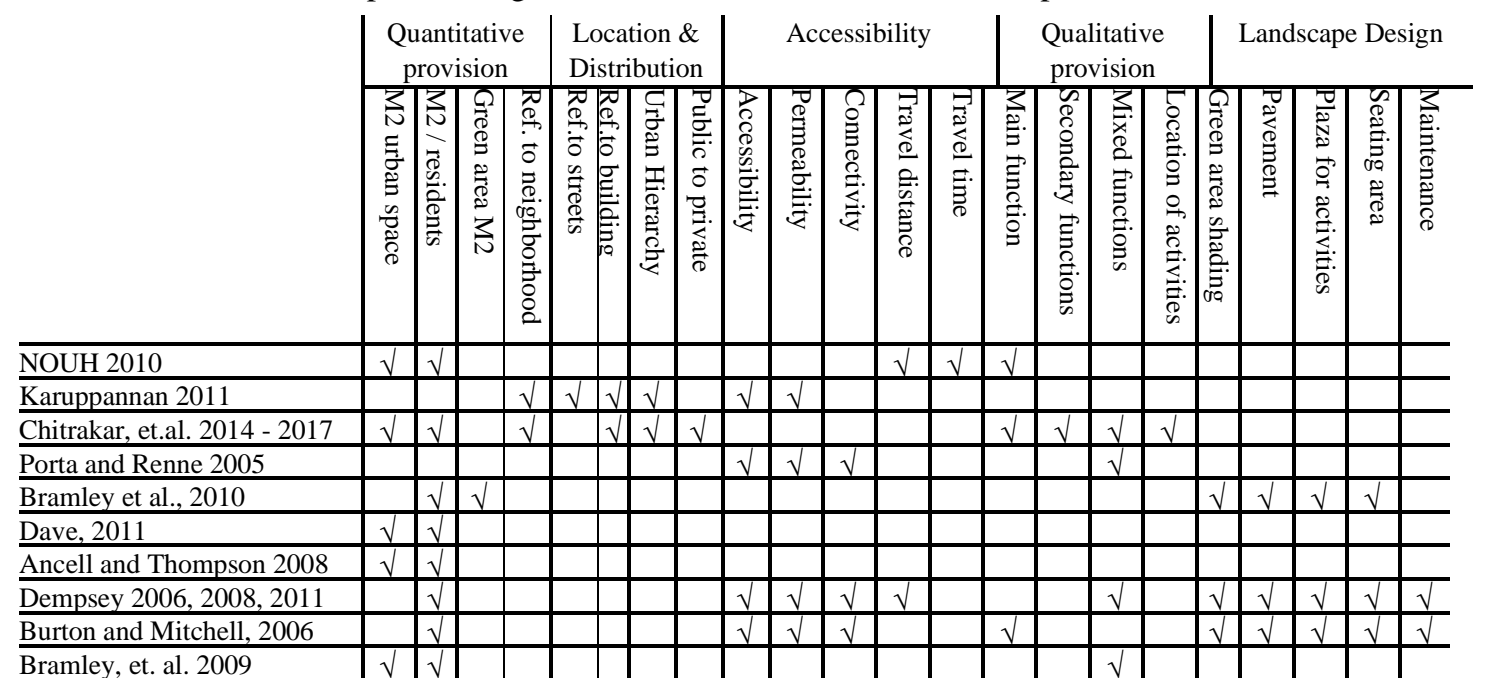

(source: author based on literature review)

Descriptive analysis is used to detect the evolution of urban spaces configuration based on spatial concepts as in table (2). Finally, justifications of the evolution from traditional to modern urban space configuration on social behavior are recorded based on theoretical base. 
Table 2. The evolution of urban spaces in different types of neighborhoods in GCR.

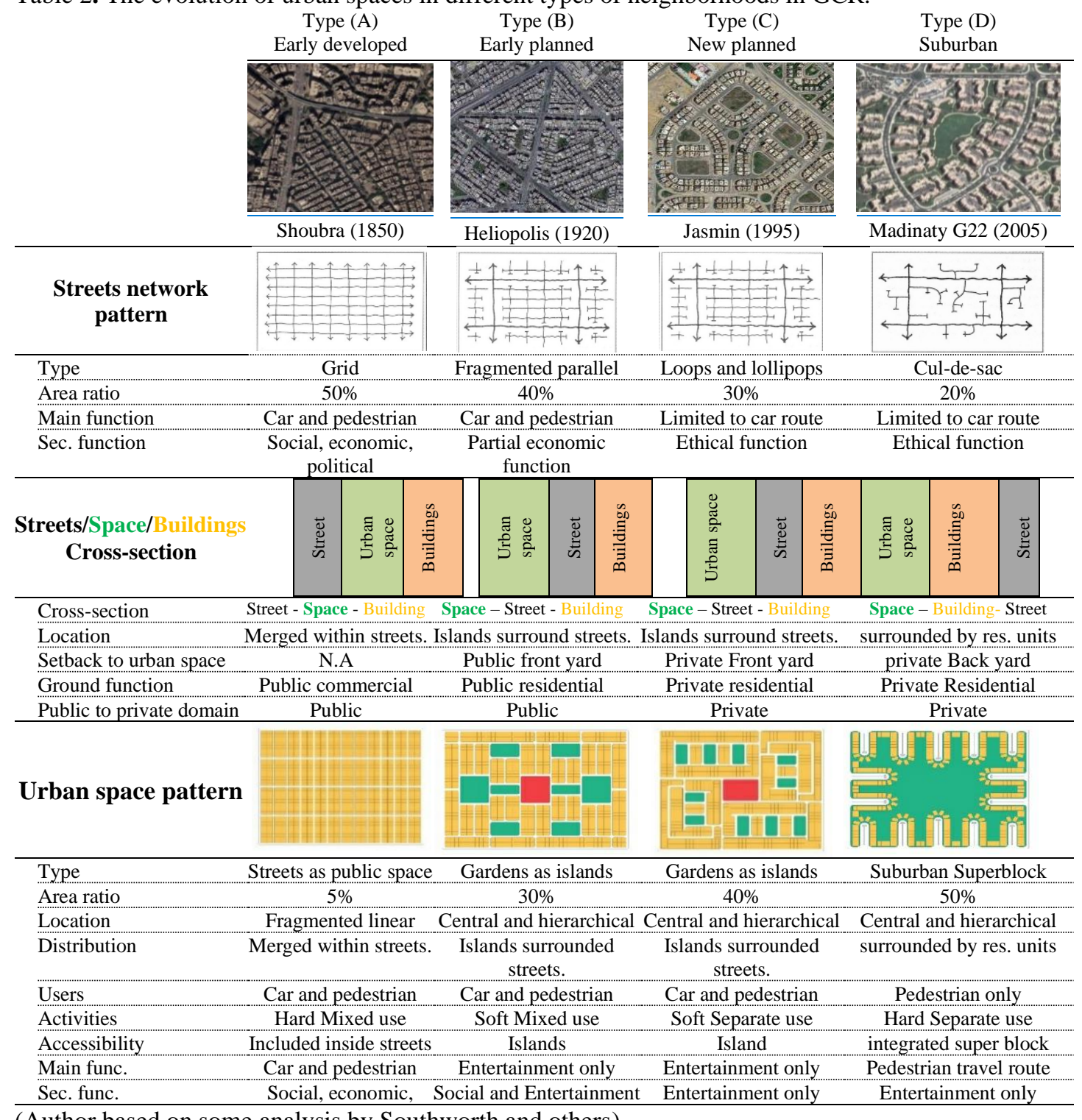

(Author based on some analysis by Southworth and others)

\subsubsection{Quantitative Provision of Urban Spaces}

It concerns sufficient size of urban spaces to fulfill needs of different integrators to perform social activities. It includes two main factors $\mathrm{m} 2 /$ person, m2/total neighborhood area. A reported evolution of urban spaces quantitative provision starts in traditional neighborhoods, streets work as public spaces that lack the proper size of urban spaces and high building footprint. In early planned neighborhoods, revealed a soft quantitative provision of urban spaces. Ending with new and contemporary planned neighborhoods that record hard provision of urban spaces with lower building density. The evolution hoped to enhance social sustainability by providing large sufficient area of urban spaces that attract residents to gather and encourage them to interact, collaborate and ensure communication between different residents to be attractive, human, and urbanized (Urbed 1997). The evolution aims to increase resident wright for more urban spaces and reduce community density and size that increase residents ability to know and recognize each other and recognize strangers in urban spaces accordingly increase their willing to know each other and engage to each other (Bahamam, 2001; Newman, 1996). 


\subsubsection{Location and Distribution of Urban Spaces}

It concerns the spatial location of urban space inside neighborhood; the spatial distribution between buildings, streets, and urban spaces; and spatial hierarchical distribution of public to private mapping. A reported evolution of urban spaces location and distribution starts in traditional neighborhood, urban spaces are merged as fragmented urban spaces organized and mixed between streets and buildings following (buildings / urban space / streets) cross-section. In modern neighborhoods, a defined central urban space located as islands separated by motor traffic streets from direct contact with front yard of buildings following (buildings / streets / urban space) crosssection. In contemporary neighborhoods a defined central internal garden merged inside superblocks and surround with direct contact with backyard of dwelling buildings away from streets and motor traffic following (streets / buildings / urban space) cross-section.

The evolution of location and distribution aimed to increase pedestrian direct contact between buildings and urban spaces and to separate pedestrian from motor traffic by excluding through traffic and exclude unwanted to provide safer streets for children and pedestrians clear of motor traffic and accordingly could enhance integrator's face to face contact. It is based on a wide claim that placing dwelling units around the public realm or common open space will increase social interaction (Karuppannan et.al. 2011; Farhadikhah et.al., 2020). It also claims that cluster closed hierarchy pattern surrounding public spaces, give the space high degree of territoriality that assure privacy and natural surveillance, make residents easily can know each other and define strangers, and are more willing to know neighbors and engage to them (Bahamam, 2001; NCPC, 2003).

\subsubsection{Accessibility to Urban Spaces}

It concerns reducing physical and visual constraints to encourage resident's involvement in urban spaces. Visual accessibility aims to increase the clear sightline for urban spaces and their access points to minimize isolation and increase attractiveness to residents. Physical accessibility aims to remove any physical obstacles for physical access such as removing barriers, reducing travel distance, effort, time, and cost for resident's inclusion (Rao, P. 2018). A reported evolution of urban spaces accessibility starts from traditional neighborhoods that increased accessibility by merging urban spaces with streets and residential buildings; to early planned neighborhoods that revealed controlled accessibility limited by fences and minimum access gates. Moving to new planned neighborhoods that revealed soft accessibility using urban space as islands separated by motor traffic street from residential buildings. Finally, contemporary neighborhoods revealed high physical and visual accessibility. The evolution of accessibility aimed to reduce motor accessibility and increase pedestrian accessibility, in the other hand to reduce non-residents accessibility to provide save community out of intrusions.

\subsubsection{Qualitative Provision of Urban Spaces}

It concerns the quality and type of activities that are allowed in urban spaces. Spatial change of urban spaces location and distribution shift the type and location of activities and the primary and secondary function exist in urban spaces. In traditional neighborhoods, streets not only work as traveling routes to connect different destinations of the city, but it also acquired multiple functions i.e. economic, 
ceremonial, political, cultural and social values; on the contrary, contemporary neighborhoods limits street functions as connecting route and exclude any possible subsidiary functions to a separate urban spaces at the backyard of the residential buildings (Allocated, L., 2013; Mboup, G., 2015). On the other hand, planners aimed to remove non-residential functions from residential area to avoid crudeness and exclude non-residents from urban spaces, to provide more security, safety and exclude unwanted, and provide safe environment for children.

\subsubsection{Quality of landscape design of Urban Spaces}

It concerns the quality of hardscape and softscape design that are well equipped with amenities and well cared with plazas, pedestrian walkways, and care of handicapper. A wide claim argue that well-designed landscape makes urban spaces inviting for gathering integrators and foster social inclusion, interaction, and participation (ODPM, 2002, 2004). Planners aimed to replace grid with hierarchal street pattern to reduce streets area and increase green area that could enhance inclusion, interaction, and participation. Furthermore, they aim to avoid through traffic inside the community and provide calm and safety for pedestrians and provide them with walkway separated from automobile to avoid cross circulation between pedestrian and cars traffic to increase pedestrian safety. Pedestrian walkways are excluded from streets and merged inside gardens to encourage foot accessibility, residents walked on landscaped footpaths, while streets were given over to the automobile. Most plaza and squares are filled with green area to provide environmental filtration to help marketing the community. The proceeding modern evolution of urban space configuration and their social intentions in social sustainability are questioned in ground of their applicability in the context of Carians residential developments.

\subsection{Egyptian Design Guidelines for Urban Spaces}

Egyptian National Organization for Urban Harmony NOUH 2010 developed standards of urban harmony for green area and open space in 2008 as shown in Table 2. The developed design guidelines concerned quantitative provision, accessibility, and qualitative provision criteria with the hope to create better community as in table (3).

Table 3. Spatial allocation of open spaces at different levels of a city

\begin{tabular}{|c|c|c|c|c|}
\hline & & Cluster level & Neighborhood level & District level \\
\hline \multirow{3}{*}{ Quantitative } & Area & $4200 \mathrm{~m} 2$ & $4200 \mathrm{~m} 2$ & $12600 \mathrm{~m} 2$ \\
\hline & Capacity & $900-1200$ person & $3000-5000$ person & \\
\hline & Rate & $0.08-0.3 \mathrm{~m} 2 /$ person & $0.8-1.66 \mathrm{~m} 2 /$ person & $1 \mathrm{~m} 2 /$ person \\
\hline \multirow{2}{*}{ Accessibility } & Travel distance & $200 \mathrm{~m}$ & $400 \mathrm{~m}$ & $1000 \mathrm{~m}$ \\
\hline & Travel time & 3 min. & $6 \mathrm{~min}$. & $15 \mathrm{~min}$. \\
\hline \multirow{2}{*}{ Qualitative } & Activities & Playground / 2000 person & Playground / 2000 person & Semi Olympic playground \\
\hline & Play area & Kids play area $100 \mathrm{~m} 2$ & Kids play area $100 \mathrm{~m} 2$ & Kids play area $200 \mathrm{~m} 2$ \\
\hline
\end{tabular}

However, the guidelines seem to be limited to give better socially sustainable solution; It seems to be developed from international context that might not be suitable for Egyptian context; It should vary depending on the developed social network of public 
spaces. An empirical knowledge about potential impacts of imported planning decision, guidelines, and spatial arrangement of urban spaces to social behavior of local community is required. This paper rests on different spatial and characteristics of neighborhoods urban spaces to test their impact on resident's social behavior.

\section{URBAN SOCIAL SUSTAINABILITY}

Sustainability agenda emerged in 1980 with limitation to environmental dimensions. Since 1990 an equal interest with economic dimension takes place. Starting with 21st century, UN habitat widens the scope to an equal interest for social sustainability with environmental and economic concerns (Colantino, 2010). The main concern of social sustainability firstly concerned tangible variables i.e. poverty, job opportunities, affordable housing, equity, and equality; later on an interest concerned intangible variables i.e. Sense of place, sense of identity, satisfaction, social inclusion, cohesion, and participation (Shirazi M, Keivani R. eds., 2019).

Urban social sustainability is an emerged concept that concerns the impacts of urban design and physical planning on social sustainability (Chan \& Lee, 2008; Davidson \& Wilson, 2009; Dempsey et al., 2011; Bramley and Power, 2009; Bramley et al., 2009). Scholars aimed to find relationship between urban form factors and urban social sustainability. UN-habitat and NGOs in the global report of human settlements, reported a paradigm shift in urban space design, it proposed the concept of "World Charter for the Right to the City" in UNESCO's Headquarters in Paris $(2005,2006)$, Barcelona (2005), Vancouver (2006), Porto Alegre (2008), Mixco charter for the Right to the City (2009), Rio de Janerio Manifesto on the Right to the City (2010); Biennial of Public Space (2013) and Gwangju (2015). These charters and manifestos call planners to make a paradigm shift to encourage new forms of urban space that builds social sustainable model based on principles of solidarity, freedom, equity, dignity, justice, transparency, participation; diversity in economic, social life, and social inclusion (Júnior, N. S. 2016).

UN-habitat charter of public space aimed to provide guideline to enhance open spaces. It defines all places publicly owned or of public use; accessible and enjoyable by all for free and without a profit motive, public space is not privately owned that do not implies profit to attract the whole community. It implies guarantee of resident's wrights to participate in collective life. It considers accessibility and diversity in urban spaces. The development of socially sustainable urban space aims to encourage social cohesion, inclusion, justice, sense of identity, and social interaction, integration, communication, and networking. It considers more than a physical space within which social processes operate; a place that enhances social relation, integration and especially face to face copresence (Júnior, N. S. 2016).

Dimensions of urban social sustainability seems very broad i.e. social justice, social solidarity, participation, and security (Thin et al. 2002); equality and social justice (Ancell at.al. 2008); Reduce inequalities and social gaps (Polèse et al. 2000); happiness, security, freedom, dignity, and affection (Khan 2016; Vavik and Keitsch 2010); Safety and security (Newman 1996); social capital (Putnam 2000); Social interaction and crime prevention (Bahamam 2001), sense of security (Kamon, Heidar, 1997); Social cohesion and social capital (Forrest and Kearns, 2001; Hills et al, 2002), social interaction, sense of place, participation, safety, equity and satisfaction (Larimian, T., 2019). 
However, Shirazi and Keivani (2019) claimed that the research in social sustainability dimensions seems very broad in coverage diversity of disciplines, geography, and scale of operation (Shirazi M, Keivani R. eds., 2019). They argue that identifying the proper relevant indicators and the quantitative and qualitative methods, depends on three main variables; the first to search in depth to the discipline; the second, to consider geographical scale that may differ from discipline to discipline; the third, is the scope of the research. They argue that define indicators appropriate for neighborhood scale may lose its significance for city and regional scale, thus depending on the scale of inquiry, from nation to community (Shirazi M, Keivani R. eds., 2019).

Review of previous studies concern urban social sustainability revealed a geographical scale shift starting with city scale (Dempsey et. al. 2012; Colantonio \& Dixon, 2009; Shariti \& Murayama, 2013; Pakseresht \& Fazeli, 2011; and Chan \& Lee, 2008) to a massive research concerning neighborhood scale (L.H.Chiu, 2003; Pongsmas. 2004; Ancell and Thompson 2008; Dempsey et. al. 2011; Bacon et. al., 2012; Dave, and 2009) and limited scientific research concerning neighborhood urban space scale. Analyses of urban social sustainability in previous studies have focused on the macro levels.

In recent years, current studies shifted the focus of the analysis to the neighborhood level. The concern of this research mainly targets urban social sustainability in urban space levels. Table (4) summarizes the deduced urban social sustainability indicators based on an extensive academic review in neighborhood and urban space scale. The deduced urban social sustainability indicators represent a classification of two types based on measurement tools. The tangible objective type that represents actual social behavior i.e. social inclusion, interaction, participation, and freedom. The other type is the intangible subjective indicators that represent resident satisfaction and sense of what they wish to have i.e. sense of identity, community, belonging, attachment, safety and security, satisfaction, and quality of life.

Table 4. urban social sustainability indicators.

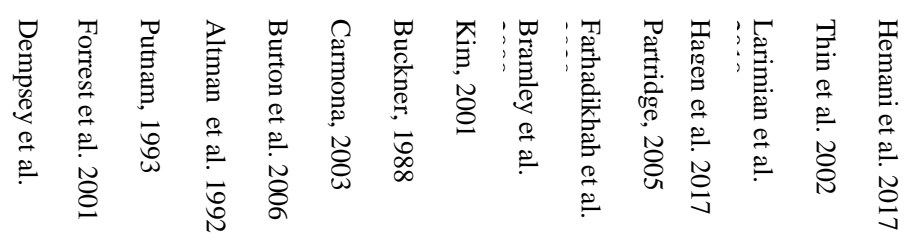

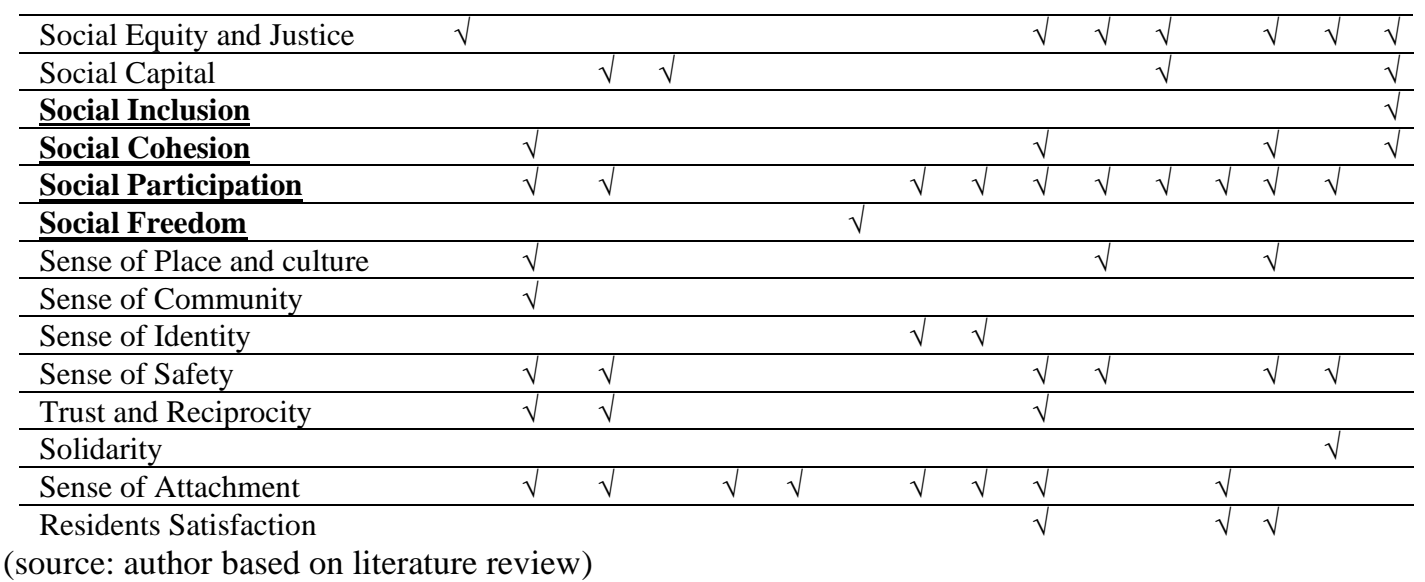

For the purpose of this study in urban spaces scale, and in order to limit the vast amount of social sustainability indicators, this research based on four proudly objective indicators of social sustainability that fit the scope of the research: social inclusion, 
cohesion, participation and social freedom received increased attention. They will be measured using tools as in Table (5):

\subsection{Urban Social Inclusion and Diversity Index}

It refers to the ability of an urban space to ensure the welfare of all community members, minimizing polarization, segregation, and exclusion (CDCS). It refers to having equal opportunities of access to urban spaces, services, and facilities, to achieve social equity in the distribution and sharing of development benefits and costs. It refers to how the neighborhood is willing to provide accessibility wright for all community members include different ages (child, adult, and elder), gender (male, and female), income (low, mid, and high), physical condition (non-disabled, and disabled). It includes types of integrators (residents, neighbors, passers, and targeters).

It refers to having equal opportunities for all integrator types to access urban spaces and participate in activities and provide attractiveness to coexist and interact. It also implies the quality and quantity of inclusion (individual inclusion, inclusion in groups). It involves functional reason for inclusion that varies between intentional social activities, social activities as subsidiary activity for other attractive activities, and social inclusion as by product of movement form destination to another (Agyeman, 2005; Harvey, 2010; Fainstein, 2010; Dempsey et al., 2012).

\subsection{Urban Social Cohesion and Interaction Index}

It refers to the ability of an urban space to sustain relationship among its residents to make them interact, know, and trust each other. It concerns increasing resident's interaction in term of (quality, quantity, type and degree of interaction) to increase social ties between city residents that promotes them to know each other, engage to their neighbors, increase the depth of their relations, increase the degree they can help each other, they can trust each other, and they can exchange their experiences with other social groups, and to make urban spaces as an effective place for socializing future generation, and for exchange and contact of knowledge, experiences, and information with other diverse social groups (Forrest \& Kearns, 2001; Hamiduddin, 2015; Dempsey et al., 2012).

This index implies the following indicators first: promoting intentional interaction by encouraging residents to invite their closer neighbors to meet in urban spaces, and to encourage accidental interaction by foster social causal counter with far distance neighbors. Second: Promoting passive contact such as seeing, hearing, and informal greetings and active contact such as building close friendship with integrators. Third: Promoting interaction with similar and diverse social groups. Fourth: Promoting interaction with different types of integrators (Gehl, J. 2011).

\subsection{Urban Social Trust and Solidarity Index}

It refers to the ability of urban space to make residents know neighbors and accordingly distinguishes who are strangers in the community. It also measures whether residents feel trust in neighbors, and other integrators, whether they thought them were fair, and try to be helpful. Furthermore, it refers to the ability of a urban space to make residents feel safe for properties, feel safe to moving in streets, parks and urban spaces for themself, families, children and wife, kids and elder people, feel safe during day hours, during night hours, till late night (Leyden et.al., 2003).

\subsection{Urban Social Participation and contraction Index}

It refers to the ability of an urban space to encourage residents to participate to different activities in urban spaces including necessary activities that happens regardless of the 
quality of urban spaces, optional activities that depends on how and what quality that urban space can provide to attract people for inclusion, and social activities. It also refers to the voluntary involvement and the ability to influence their community and impact political and social decision making, individually or collectively regarding their community. It includes the type of adopted regulation that could give them limit in their action. (Agyeman, 2005; Harvey, 2010; Fainstein,2010; Dempsey et.al., 2012; Forrest et.al., 2001; Griessler 2005; Gehl 2006,2011).

\subsection{Urban social Freedom Index}

It refers the freedom that urban spaces can provide residents to be free to access, move, occupy, and act different activities at any time. It implies resident's ability for partially or totally change their community to express themselves and achieve their needs (Carr et.al., 1992; Carmona, 2003).

Table 5. Social Sustainability Measures. ASSESMENT SOCIAL INDICATORS

\section{VARIABLE AS OBSERVED OR ASKED IN QUESIONAIR}

\begin{tabular}{|c|c|c|}
\hline \multicolumn{3}{|c|}{ Social Inclusion in urban space } \\
\hline \multirow{5}{*}{$\begin{array}{l}\text { Diversify } \\
\text { of inclusion }\end{array}$} & I01 Diversity of Age & Observed no. of person per (child, adult, and elder) (times/day/type) \\
\hline & I02 Diversity of Gender & Observed no. of (male and female). (times/day/type) \\
\hline & I03 Diversity of Income & Observed no. of (low, medium, and high) income. (times/day/type) \\
\hline & I04 Diversity of Integrators & Observed no. of (residents, neighbors, passers, targeter) (times/day/type) \\
\hline & I05 Diversity of Physical Condition & Observed no. of (non-disabled and disabled) (times/day/type) \\
\hline \multirow{2}{*}{$\begin{array}{l}\text { Type of } \\
\text { inclusion }\end{array}$} & I06 Inclusion as individuals & Observed no. of inclusion as individuals (times/day/type) \\
\hline & I07 Inclusion in groups & Observed no. of inclusion in groups (times/day/type) \\
\hline \multirow{3}{*}{$\begin{array}{l}\text { Purpose of } \\
\text { inclusion }\end{array}$} & I08 Intended social activity & I exist in urban space for social interaction purposes (Times/day). \\
\hline & I09 Subsidiary to other activities & I exist in urban space for non-social activities (Times/day). \\
\hline & I10 By-product of movement & I exist in urban space while moving to other distention (Times/day). \\
\hline \multicolumn{3}{|c|}{ Social Cohesion in urban space } \\
\hline \multirow{5}{*}{$\begin{array}{l}\text { Social } \\
\text { Interaction }\end{array}$} & C01 Intentional interaction & I invite my neighbors to contact them in urban spaces (Likert 1-5) \\
\hline & C02 Accidental interaction & I accidentally meet my neighbors in urban spaces day and night (Likert 1-5) \\
\hline & C03 Individual interaction & I used to meet individual persons in urban spaces (Likert 1-5). \\
\hline & C04 Collective interaction & I used to meet groups of my neighbors in urban spaces (Likert 1-5). \\
\hline & $\begin{array}{l}\text { C05 Integrators diversity interaction } \\
\text { C06 Social diversity interaction. }\end{array}$ & $\begin{array}{l}\text { I used to meet neighbors, residents, passers, targeters interaction measure. } \\
\text { Between similar social groups, and Between different social groups. }\end{array}$ \\
\hline \multirow{10}{*}{$\begin{array}{l}\text { Social } \\
\text { Solidarity }\end{array}$} & C07 Recognize neighbors measure & I can easily recognize neighbors (Likert $1-5$ ). I invite my neighbors to vacations \\
\hline & C08 Social engagement measure & I invited my neighbors to my home, \\
\hline & C08 Know Strangers Measure & I can recognize strangers and I am familiar with Strangers (Likert 1-5). \\
\hline & C09 Define Offenders Measure & I can define offenders (Likert 1-5). \\
\hline & C10 Trust in integrators & I trust strangers and trust them (Likert 1-5). \\
\hline & C11 Engage with integrators & If any of integrators needs help I will do.(Likert 1-5). \\
\hline & C12 Think they are helpful & If I need help, I will ask my neighbors (Likert 1-5). \\
\hline & C13 Natural Surveillance Measure & Resident's inspection of external surroundings from inside home (Likert 1-5). \\
\hline & & \\
\hline & C15 Sense of safety in urban spaces & I feel safe in streets and urban spaces (self-safety, property, at night, at day). \\
\hline \multicolumn{3}{|c|}{ Social Participation in urban space } \\
\hline \multirow{3}{*}{$\begin{array}{l}\text { Type of } \\
\text { Activities }\end{array}$} & P01 Necessary Activities & I participate in Economic, work, educate, political and shopping (Likert 1-5) \\
\hline & P02 Optional Activities & I participate in sport and entertainment (Likert 1-5) \\
\hline & P03 Social Activities & I participate in Mary, success, death, birth, and religion celebration. (Likert 1-5) \\
\hline \multirow{3}{*}{$\begin{array}{l}\text { Social } \\
\text { Participate }\end{array}$} & P04 Effort to solve problems & I care about solving problems in my community by effort \\
\hline & P05 Money to solve problems & I care about solving problems in my community by mony \\
\hline & P06 Time to solve problems & I care about solving problems in my community by time \\
\hline \multirow{3}{*}{$\begin{array}{l}\text { Political } \\
\text { Participate }\end{array}$} & P07 Influence decision making & I participate in formal and informal way to attend meetings (Likert 1-5) \\
\hline & P08 Owners union & I care to be one of the owner's union (Likert 1-5) \\
\hline & P09 Participate in elections & I participate in elections (Likert 1-5) \\
\hline \multirow{2}{*}{$\begin{array}{l}\text { Type of } \\
\text { participate }\end{array}$} & P10 Individual participation & The design of urban space area limited to individual activities (Likert 1-5) \\
\hline & P11 Collective participation & The design of outdoor area suits different social and cultural groups (Likert 1-5) \\
\hline \multicolumn{3}{|c|}{ Social Freedom in urban space } \\
\hline \multirow{2}{*}{$\begin{array}{l}\text { Free of } \\
\text { change }\end{array}$} & F01 Minor changes in design & I can make minor modification to urban spaces (Likert 1-5) \\
\hline & F02 Major changes in design & I can make major modification to urban spaces (Likert 1-5) \\
\hline \multirow{3}{*}{$\begin{array}{l}\text { Free of } \\
\text { action }\end{array}$} & F03 Free of access & I can freely access to urban spaces (Likert 1-5) \\
\hline & F04 Free of movement & I can freely move in urban spaces (Likert 1-5) \\
\hline & F05 Free of action & I can freely make activities in urban spaces (Likert 1-5) \\
\hline
\end{tabular}

(source: author based on literature review) 


\section{A CASE STUDY OF FOUR TYPES OF URBAN SPACES IN GCR}

The objective of this research is to trace any significant differences in responses to social sustainability indicators across different types of urban spaces inside different neighborhoods.

\subsection{Selection of Case Study Areas}

Selection of case study based on four main criteria's:

(a) It should present different prototypes i.e. traditional early developed, early planned, new planned and contemporary private communities.

(b) It should provide diversities of urban space configuration in term of quantitative; location, distribution, accessibility; and qualitative criteria.

(c) It should represent different income levels in each prototype.

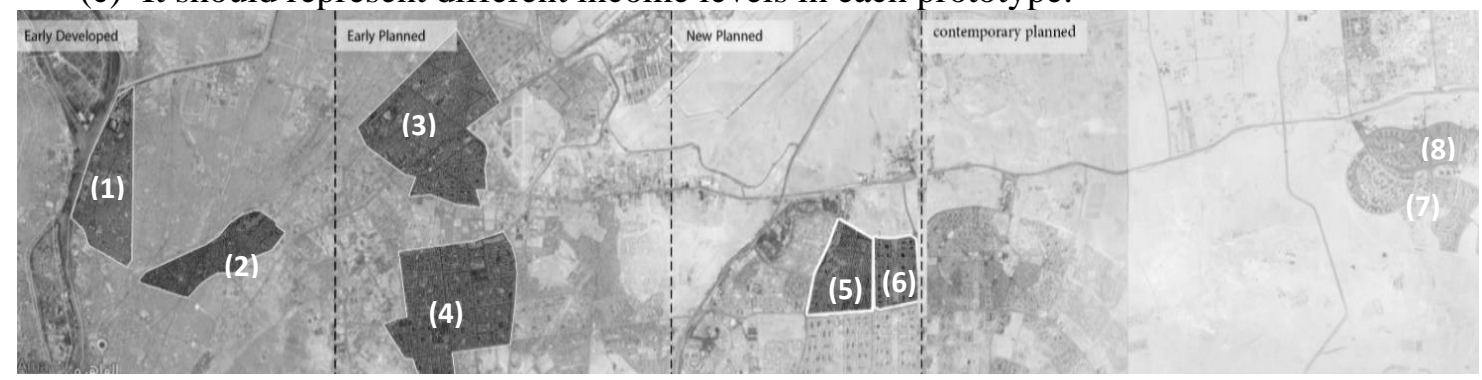

Fig. 1 Selected Case study, Different patterns of urban spaces. (source: google map edited by author)

Based on the previous criteria, eight neighborhoods (NH1 to NH8) are selected to represent four prototypes, two in each prototype. Figure (1) and (2), represents selected four types of urban spaces in different categories of neighborhoods in GCR:

- Khalfawy in Shoubra are selected to represent early developed neighborhood.

- Nasr City and Heliopolis are selected to present early planned neighborhood.

- 1 st district and Jasmin in New Cairo are selected to present new planned neighborhood.

- P11 and P22 in Madinaty are selected to present private gated neighborhood.

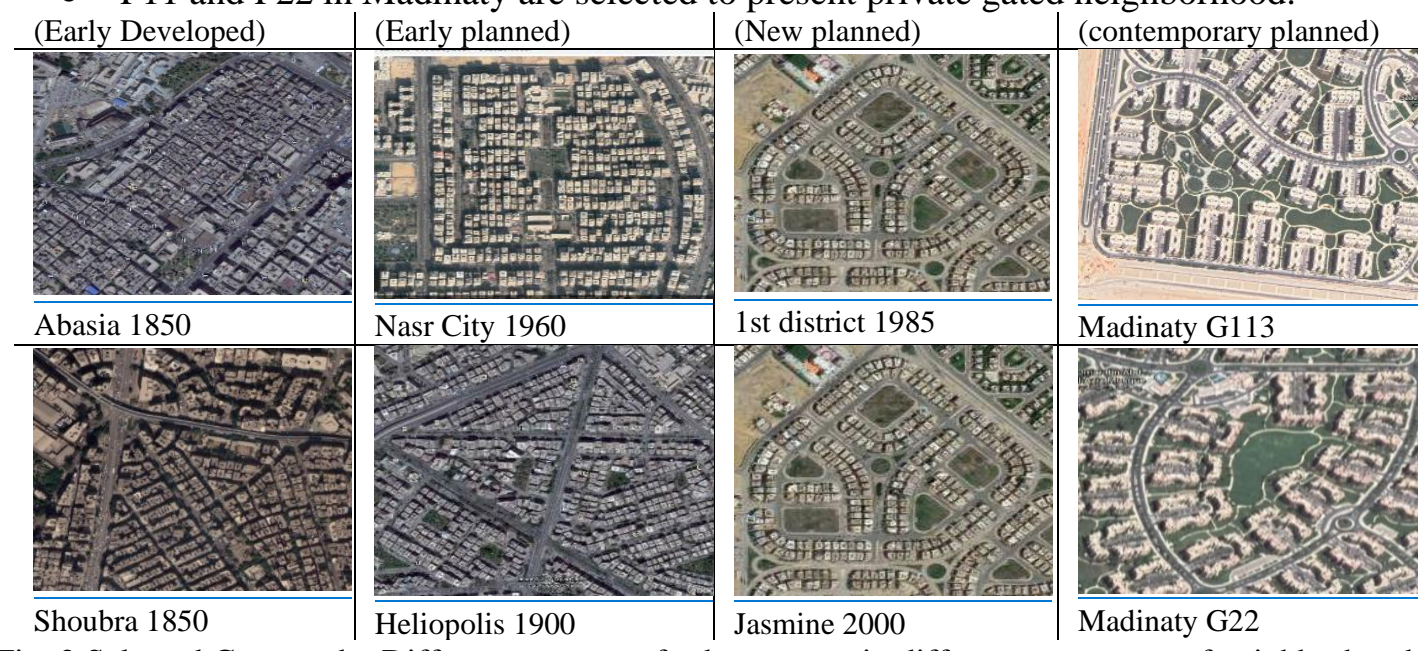

Fig. 2 Selected Case study, Different patterns of urban spaces in different prototypes of neighborhoods. (source: google map)

\subsection{Data Collection and Classification}

The purpose of this research is to measure the impact of urban spaces configuration on achieved urban social sustainability. Data collection were conducted at the selected setting from 1 to 30 February 2020. Two forms of data collection were used - the first to measure patterns of urban space configuration, and the other to measure social 
inclusion, interaction, and participation in neighborhood. Finally, the correlation between both is deduced.

\subsubsection{Measurements of Urban Spaces Configuration}

This part proposes to measure urban space patterns represented in quantitative provision of urban spaces, accessibility, and qualitative provision of urban spaces. It starts with used measuring tools for each variable and the collected data. Urban form data were collected using surveying maps, observation, satellite maps, photographic images to document urban space patterns including.

- Quantitative provision of urban spaces: (rates m2/person, m2/neighborhood area).

- Location and distribution of urban spaces (hierarchy of urban, public to private mapping).

- Accessibility: (walk score, distance score, time score, physical and visual accessibility).

- Qualitative provision of urban spaces: (included activities variation).

- Landscape design and street furniture: (garden type, hardscape type, furniture design).

All previous measures are used to create a variable "Urban Space Configuration Measure". It has been gathered, measured, and scored in percentage in table (6).

\subsubsection{Measurements of Sustainable Social Behavior}

Measuring social behavior is a critical issue that requires different investigation tools, the research depends on two types of data collections to give clear conclusion for measuring social and human behavior, both tools provide validation for each other as follow:

\subsubsection{Ethnographic observation}

It is a tool used to observe social behavior, and human daily-life activities (Low et.al. 2005). These data were gathered in an evaluation sheet of each urban space during three times of the day 9.00 to $9.15 \mathrm{am}, 2.00$ to $2.15 \mathrm{pm}, 6.00$ to $6.15 \mathrm{pm}$. The observation concerns defining visitors, their types, and numbers per day. The way they visit (individual, collective), the activity they practice (economic, entertainment, social, religion). Also, observation concerns weekend, and vacations selected photos used to document data as Figure (3).

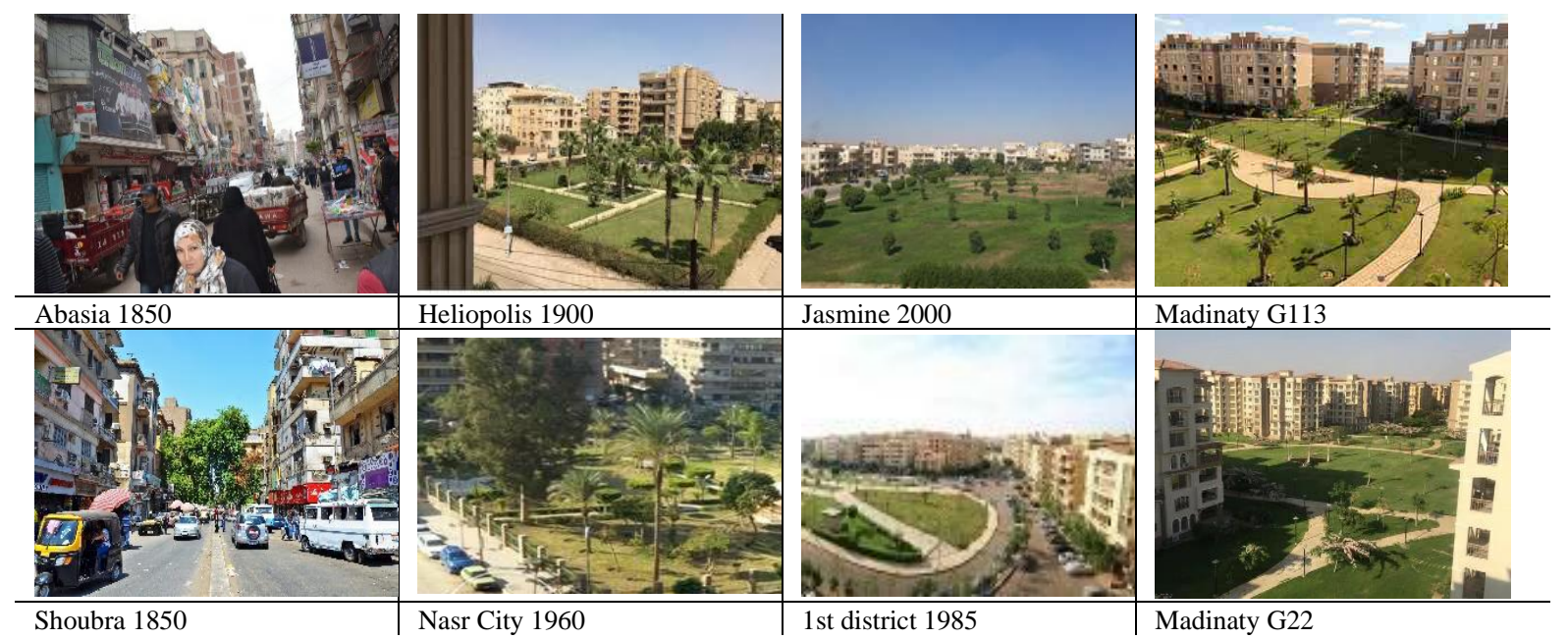

Fig.3. Different patterns of urban spaces in Greater Cairo Region: a) Shoubra (Early Developed NHs). b) Nasr City (Early Planned NHs). c) 1st district (New Planned NHs). d) Madinaty (Contemporary Neighborhood). 


\subsubsection{Questionnaire and Interview}

Questionnaire and interview are administered to urban space visitors a sample selection of 40 visitor. They are randomly selected in each case study area to represent different gender, age, and income. The questionnaire first explores resident's socio-economic characteristics then it investigates key factors of social sustainability indicators regarding (social inclusion, social interaction, social solidarity, social participation, and social freedom). Integrators are asked to rank their answers on five-point Likert scale ( 1 to 5 ) ranging from $1=$ strongly disagree, $2=$ disagree, $3=$ neutral, $4=$ agree and $5=$ strongly agree. This scale was used to compute each social indicator, and the average scores have been converted into percentage scale. A central tendency using mean score is used to represent recorded scores for each indicator in each neighborhood. All previous measures are used to create a variable called "social sustainability behavior measure". It has been gathered, measured, and scored in percentage in table (7).

Table 7. Social Sustainability Indicators Measures

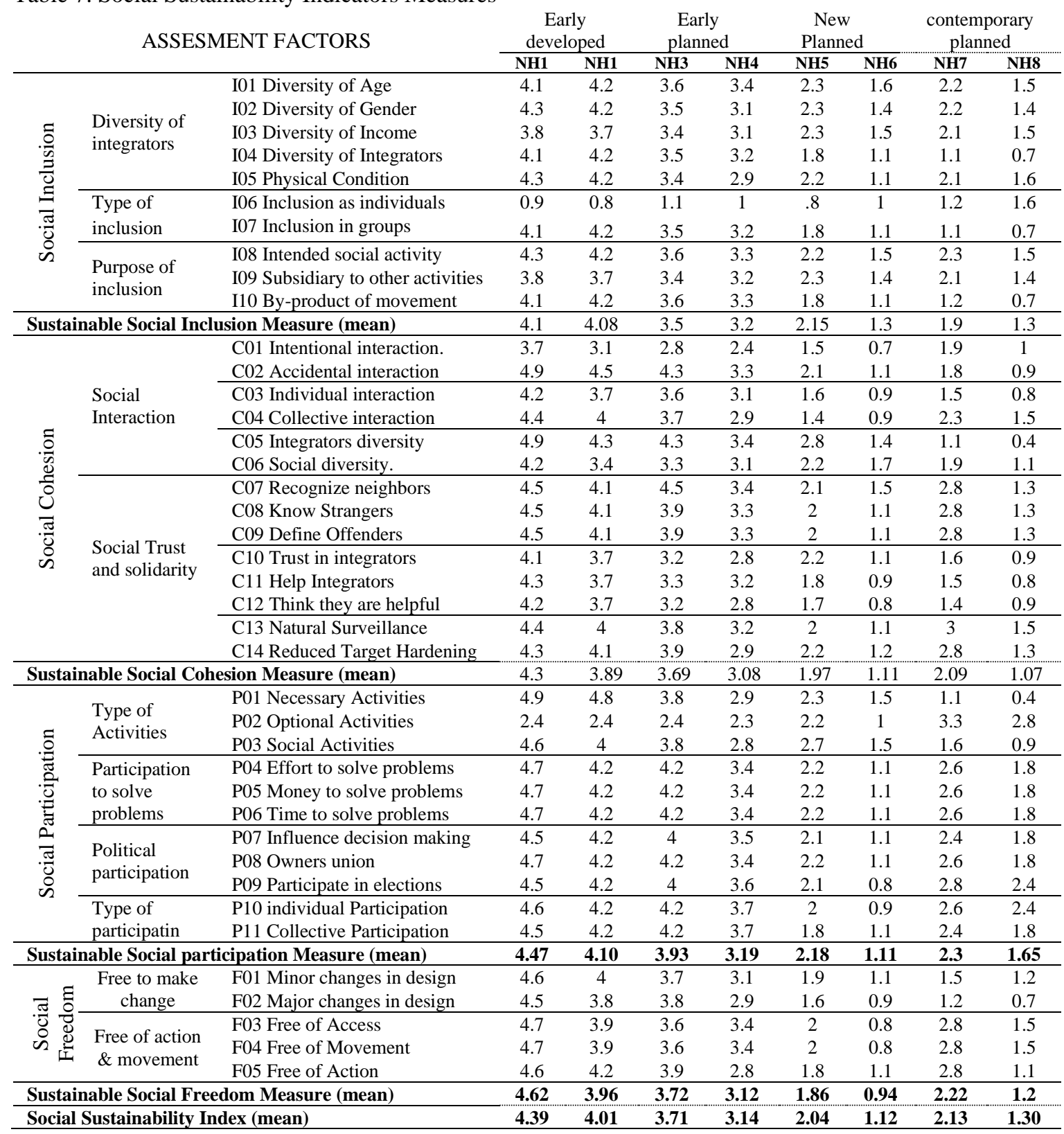

(source: author) 
Table 6. Different patterns of urban spaces in Cairo development stages.

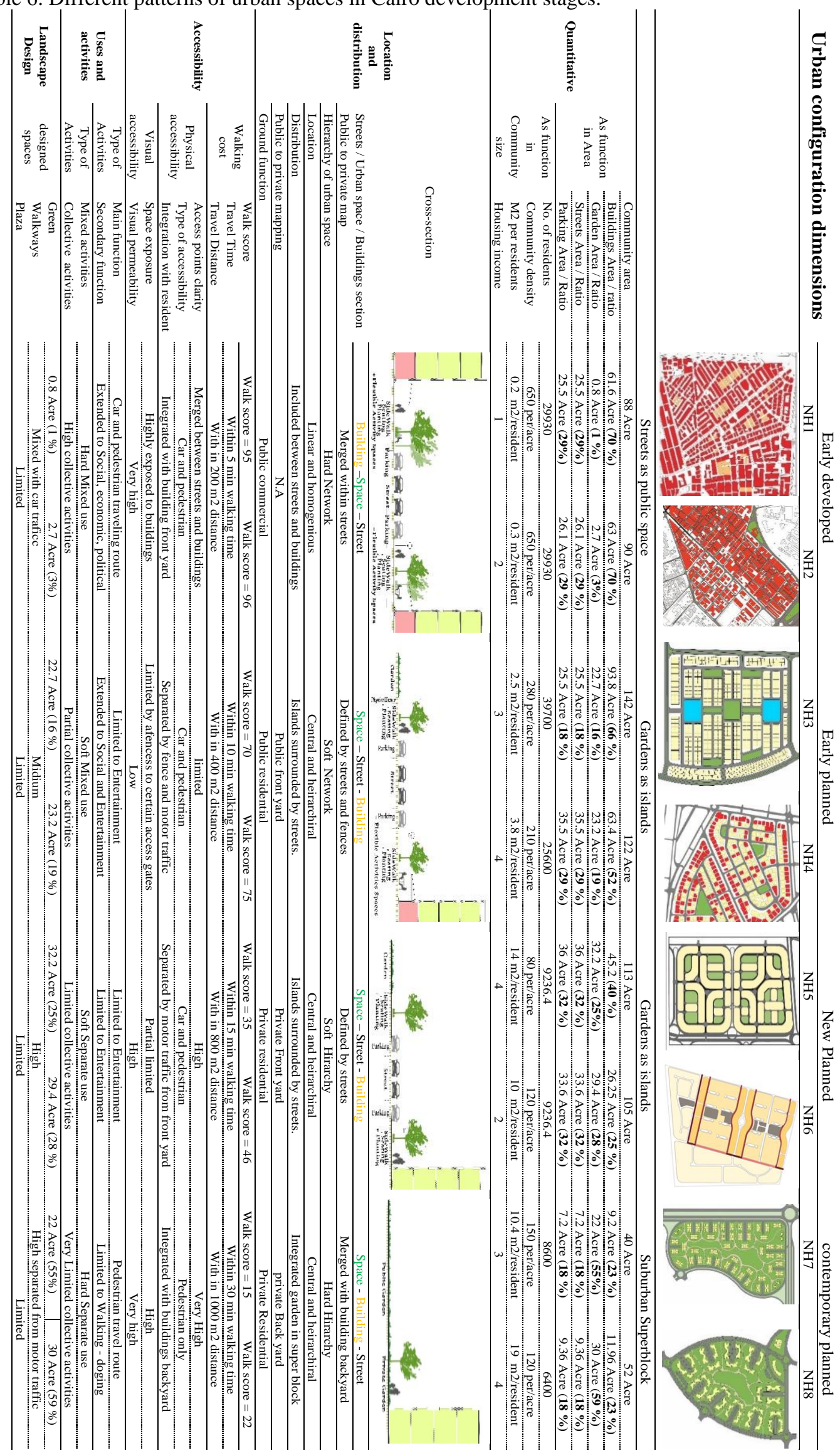

(source: author) 


\section{RESULTS AND DISCUSSION}

Based on the collected data, this part aims to discuss two interlocking stages. The first to define how social sustainability indicators varies across different types of urban spaces, the second to trace the impacts of urban space configuration on achieved social sustainability.

\subsection{Tracing the Variation of Social Sustainability Across Urban Spaces}

This part aims to discuss how social sustainability varies across different models of urban space in terms of social inclusion, social cohesion, and social participation.

\subsubsection{Social inclusion in urban spaces}

Figure (4) reveals that urban spaces in traditional neighborhoods provide high values of social inclusion; they record diversity in terms of age, income, and types of integrators. On the other hand, moving to superblock, reveals limited social inclusion that mainly individual, and a homogeneity of included integrators mainly residents and limited to children and elders, as follow:

(a) Figure (4-a) reveals that people are more willing to collectively involve spending time in groups in traditional urban spaces than in modern and contemporary urban spaces where they are willing to be individually involved to spent time alone. Further it reveals that people are more encouraged for age diversity of inclusion where kids, adults, young and elders recorded in streets all day and night in traditional urban spaces than in new and contemporary urban spaces that are limited on kids and elders.

(b) Figure (4-b) reveals that people are more encouraged for social diversity where different income i.e. low, mid and high income are included in traditional urban spaces that new and Contemporary one that recorded social segregation and lower income diversity excluding who are not similar.

(c) Figure (4-c) reveals that diversity of integrators are more encouraged for inclusion where a variety of residents, adjacent community neighbors, passers, and targeters are recorded in traditional urban spaces than new and contemporary one that are limited to residents.
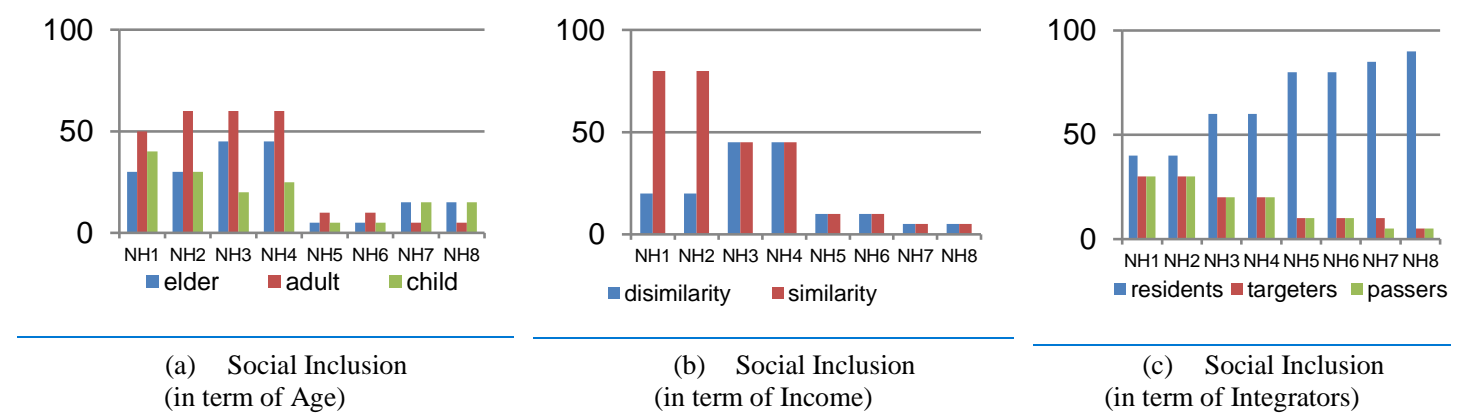

Fig. 4. The variation of social inclusion indicators across neighborhoods (source: author).

Figure (5) reveals that intended social inclusion compared to other accidental inclusion types records lower values in all prototypes where residents record low interest to be included in urban spaces for only intentional social activity that happen by invitation. Most social inclusion in urban spaces is accidental activities depending on inclusion as subsidiary activity for other attractive activities, and as by product of different modes of movement. Traditional urban space succeeded to encourage social interaction as subsidiary for great amount of public and collective activities and can encourage pedestrian movement behavior. On the other hand, new planned and contemporary urban spaces are limited to intended purposes which are limited: 
(a) Figure (5-a) reveals that people have no interest for intended social interaction in all types of urban space compared to the other two purposes for social inclusion. A relative lower interest to build intended social activities for collective celebration and participation in different social activities is recorded in traditional urban spaces than in new and contemporary urban spaces where residents have low interest.

(b) Figure (5-b) reveals that people drawn to practice social activity as subsidiary to other commercial, economic and retail activities, where a great diversity activates urban spaces can encourage them to be included and interact in traditional urban spaces than in modern and contemporary one.

(c) Figure (5-c) reveals that people are encouraged to practice social activity as by product of movement in traditional urban space where residents are highly encouraged to depend on walkability in most of their travel modes, it increase chances for their inclusion in urban spaces and increases chances they can meet their neighbors and interact with them.
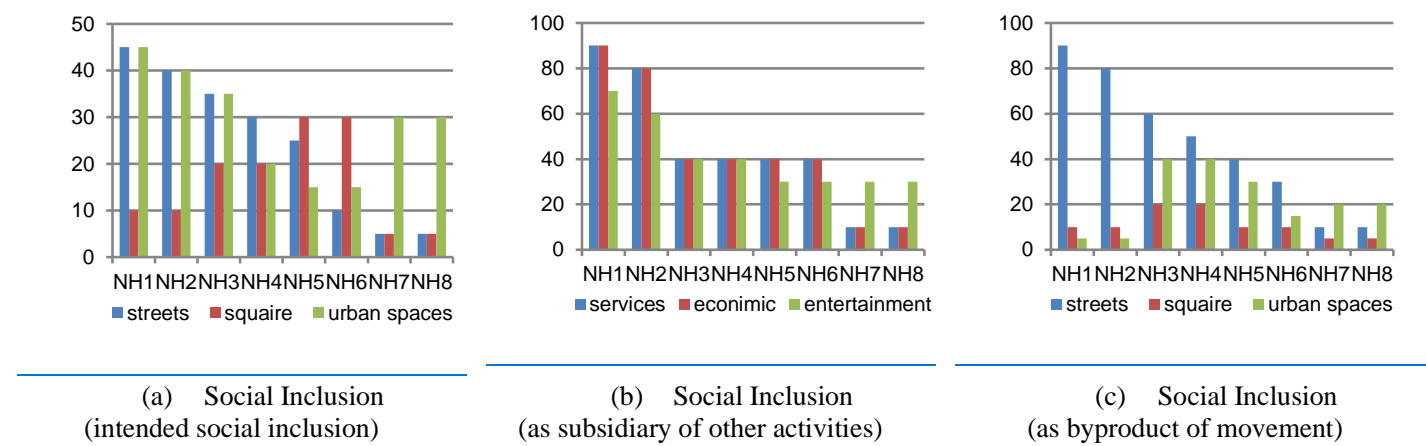

Fig. 5. The variation of social inclusion indicators across neighborhoods (source: author).

\subsubsection{Social cohesion in urban spaces}

Figure (6) reveals that moving from streets as public space to superblock, residents willing to interact inside urban spaces is reduced and interaction is limited to intentional interaction that happens between residents of similar class and in individual manner.

(a) Urban spaces in early developed neighborhoods recorded higher social interaction levels. These values are gradually reduced to lower values in contemporary neighborhoods where residents hardly know their neighbors. Urban spaces in early developed neighborhoods recorded higher intentional and accidental interaction levels. These values are reduced to lower values in contemporary neighborhoods that records low interest for intentional interaction and lower probability for accidental interaction levels.

(b) Urban spaces in early developed neighborhoods recorded higher social interaction between diversity of income i.e. low and mid income. These values are reduced in urban spaces of new planned neighborhoods that limit social interaction to residents of similar income.

(c) Urban spaces in traditional neighborhoods records great diversity of social interaction in terms of age where kids, adult, and elders in streets all day and night. These values are reduced with moving to urban spaces of new planned and contemporary neighborhoods that limit social interaction between residents of similar income, as shown in figure (6-b). Urban spaces in traditional neighborhoods records great diversity of integrators where a variety of residents, adjacent community members, passers, and targeters are recorded. These values are reduced with moving to urban spaces of new planned neighborhoods that limit social interaction between only residents, and discourage other types of integrators, as shown in figure (6-c). 


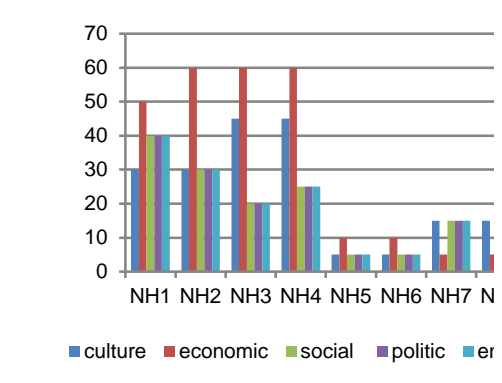

(a) Social Interaction (intentional-accidental)

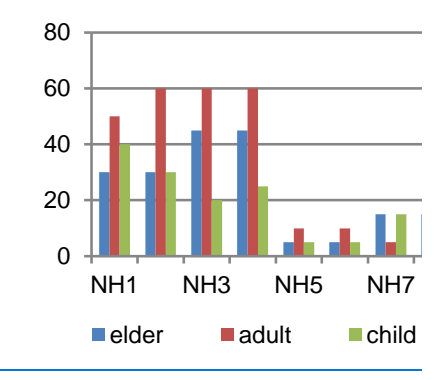

(b) Social Interaction (individual - collective)

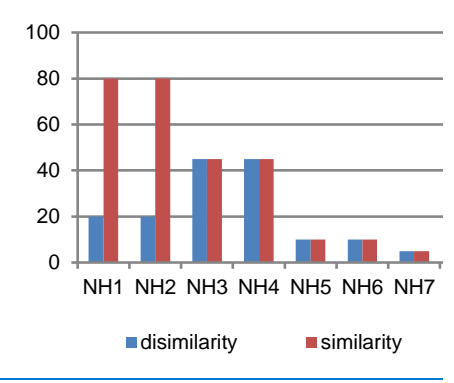

(c) Type of Interaction (similar - dissimilar income)

Fig.6 The variation of social Interaction indicators across neighborhoods (source: author).

\subsubsection{Social trust and solidarity in urban spaces}

Figure (7) explores the variation of three types of social trust and solidarity a cross different types of neighborhoods (Natural/artificial surveillance - Social trust and solidarity - Define integrators).

(a) Figure (7-a) reveals that natural surveillance and target hardener are reduced by moving from urban spaces of traditional to modern and contemporary neighborhoods, the first achieve surveillance naturally by residents who can inspect the external surroundings when they are inside their homes, and the second achieve surveillance actively or paid surveillance based on target hardening using cameras and security members in each garden.

(b) The indicator (define integrators) reveals a reduction in all cases, the first increase through pass and increases non-community persons accordingly residents can define neighbors but hardly can recognize strangers. The second make residents depend completely on car movement to cover large moving distances, accordingly, reduces moving pedestrian accordingly residents hardly can define neighbors and hardly can recognize strangers. On the other hand, urban spaces in early planned neighborhoods residents can recognize both neighbors and strangers.

(c) The indicator (social trust) records gradual reduced values with moving from traditional to new and contemporary urban spaces, as shown in figure (7-c).

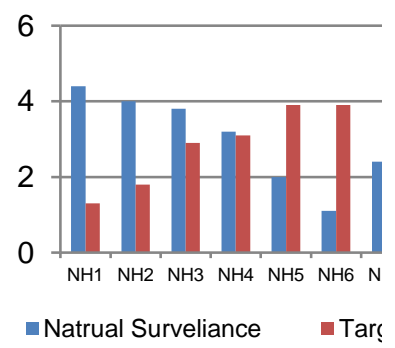

a) Natural surveillance

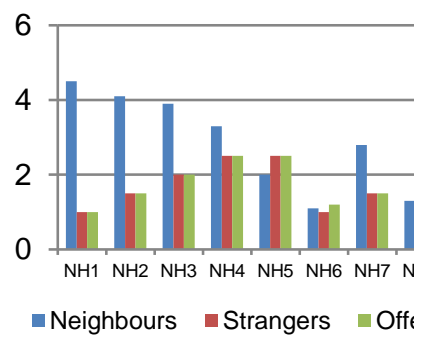

b) Define integrators

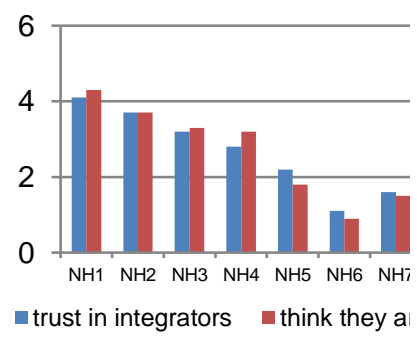

c) Social trust and solidarity

Fig. 7 The variation of social safety and security indicators across neighborhoods (source: author).

\subsubsection{Social participation and contraction in urban spaces}

Figure (8) explores the variation of social participation and contraction across different types of neighborhoods (type of activities, cost of solving community problems, decision making, political activities and elections).

(a) Figure ( 8 a) reveals the difference between resident's willingness to participate different types of necessary, optional, and social activities in case studies. Traditional urban space is encouraging people participation to all types of activities including necessary, optional, and social activities, on the contrary, modern, and contemporary urban space restrict inclusion to optional activities which are limited. 
- The indicator (Participation in necessary activities) recorded higher values in traditional urban spaces where most of the necessary activities are included in urban spaces e.g., working, shopping, education and other necessary activities and most residents participate using walkability, on the contrary most of the necessary activities are not included in modern and contemporary urban space.

- The indicator (Participation in optional activities) recorded lower values in traditional urban spaces where residents are missing entertainment activities, on the other side, it records low values in contemporary urban spaces, where residents do not have interest to participate recreational and entertainment activities even though they have large well designed urban spaces, rather they lose interest to participate compared to urban spaces in traditional neighborhoods.

- The indicator (participation in social activities) records higher values in traditional urban spaces where residents participate their happiness and sadness, celebrate religion occasions e.g., Ramadan, Eid Fetr, and Eid Adha, participate social occasion e.g., success, wedding ceremony and funeral ceremony, participate economic activities e.g., temporary market and finally participate entertainment activities e.g., playing area for kids. An individual and collective participation are recorded with higher values and extended to a variety of social, culture, religion, and economic activities. On the contrary, moving to modern and contemporary urban spaces, social participation is limited to limited individual participation in entertainment activities e.g., walking and dogging. Urban spaces failed to encourage accidental participation, failed to encourage collective participation in social, economic, cultural, and political activities.

(b) The indicator (Financial, time and effort participation in solving community problems) recorded lower values in traditional and contemporary neighborhoods where resident is not willing to participate to solve the community problems. Residents in traditional spaces have more interest in community participation than in modern neighborhoods, a higher social participation are recorded in traditional neighborhoods. the more one regards others as trustworthy and expects reciprocal benefit from others, the more likely s/he is to cooperate with others to act collectively for public good, as shown in figure (8-b).

(c) The indicator (Political participation in decision making, political activities and elections) recorded high values in traditional urban spaces where most election ceremony's happen in streets. Moving to modern and contemporary neighborhoods, a reduced value of political activates are recorded. Urban space in new planned neighborhoods concerns only to aesthetical aspects, it fails to meet any political action. They failed to have any individual or collective action in their community, as shown in figure (8-c).

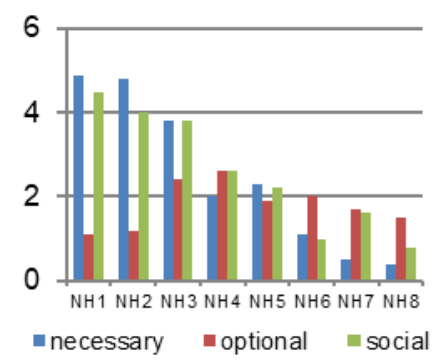

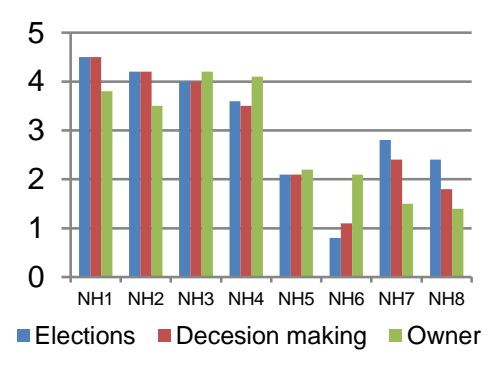

b) participation in Political action (Elections - Decision- Owners union)

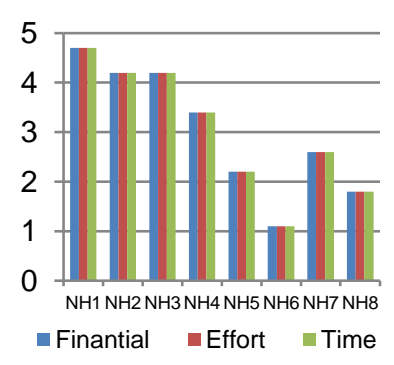

c) participation solve using (Financial - Effort - Time)

Fig. 8 The variation of social participation across neighborhoods (source: author). 


\subsubsection{Social freedom in urban space}

Figure (9) explores the variation of three types of social freedom a cross different types of neighborhoods (free to make minor and major changes, free of action, free of movement).

(a) The indicator (Free to make minor and major changes) records higher values in early developed neighborhoods where residents can make change to the spaces facing their buildings; they can make their economic activities and create shared spaces between residents for common actions. On the contrary, contemporary neighborhoods recorded lower values due to the strict regulation's developers put on them, they are not allowed to use the front yard of their building unless they pay its cost and they should obeying developer roles for organizing resident use of that space, as shown in figure (9-a).

(b) Traditional urban spaces depend on common regulation between residents that keep resident's wright to impact decisions regarding their community. Neighbor wright is governing resident's relations and impacts urban spaces. On the other hand, modern urban spaces obey intended regulation that limit resident's wright to impact decision making and make them obey municipalities' written regulations. Finally, contemporary urban space obeys the unwritten regulation by developers that make residents failed to impact decision related to community.

(c) The indicator (free of movement and free of action) recorded higher freedom of movement in traditional urban spaces. On the contrary, new planned neighborhood residents found that residential territoriality of ground floor apartments of front yard makes limitations for them while using public spaces for action and make limitations for movement in front of the ground floor private garden, as shown in figure (9-c).

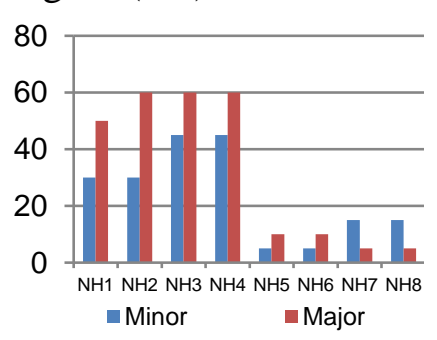

a) Free to make changes (Minor - Major)

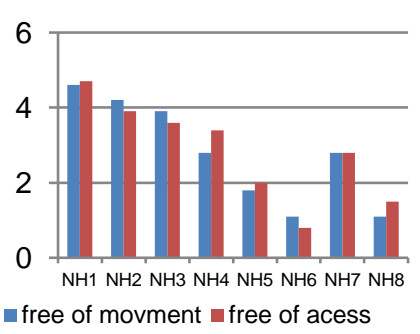

b) Free of movement (Access - Movement)

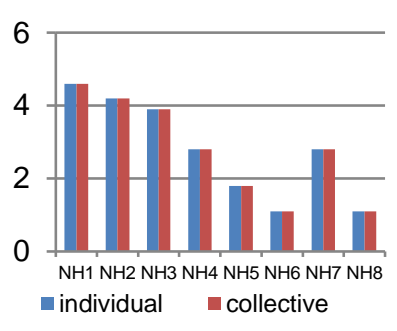

c) Free of action (Individual - Collective)

Fig.9 The variation of social Freedom across neighborhoods (source: author).

\subsection{Guidelines To Support Urban Social Sustainability In Urban Spaces}

The following part aims to discuss the correlation exists between urban spaces configuration and achieved urban social sustainability as a step to develop urban space guidelines in term of qualitative, location, distribution, accessibility, quantitative, and well-designed urban spaces. The correlation measures the degree of association between the two variables by Pearson's bivariate correlation coefficients and two-tailed significance test. The correlation measures the degree and orientation exist between variables. A strong relationship deduced between the two variables when correlation close to 1 , and a weak relation between the two variables are deduced when correlation is close to 0 to indicate. On the other hand, a positive correlation is deduced when $(+)$ value is recorded, and a negative correlation is deduced when (-) value is recorded. Table (8) present the deduced correlation between urban space characteristics and urban social sustainability. 
Table (8). Correlation between urban spaces characteristics and sustainability dimensions.

\begin{tabular}{|c|c|c|c|c|c|c|c|}
\hline \multicolumn{3}{|c|}{ Urban space characteristics } & $\begin{array}{c}\text { Social } \\
\text { Inclusion }\end{array}$ & $\begin{array}{c}\text { Social } \\
\text { Interaction }\end{array}$ & $\begin{array}{c}\text { Social } \\
\text { Participation }\end{array}$ & $\begin{array}{c}\text { Social } \\
\text { Democracy }\end{array}$ & $\begin{array}{c}\text { Social } \\
\text { Sustainability }\end{array}$ \\
\hline \multirow{8}{*}{ 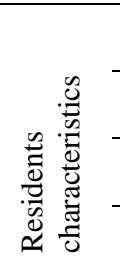 } & \multirow{2}{*}{$\begin{array}{c}\text { Community } \\
\text { Age }\end{array}$} & \multirow{2}{*}{$\begin{array}{c}\text { Correlation } \\
\text { Sig. (2-tailed) }\end{array}$} & $.910 * *$ & $.906^{* *}$ & $.889^{* *}$ & $.905^{* *}$ & $.902 * *$ \\
\hline & & & 0.002 & 0.002 & 0.003 & 0.002 & 0.002 \\
\hline & \multirow{2}{*}{$\begin{array}{l}\text { Community } \\
\text { size }\end{array}$} & \multirow{2}{*}{$\begin{array}{l}\text { Correlation } \\
\text { Sig. (2-tailed) }\end{array}$} & $-.725^{*}$ & -0.694 & -0.681 & -0.697 & $-.708 *$ \\
\hline & & & 0.042 & 0.056 & 0.063 & 0.055 & 0.050 \\
\hline & \multirow{2}{*}{$\begin{array}{c}\text { Residential } \\
\text { Density }\end{array}$} & \multirow{2}{*}{$\begin{array}{c}\text { Correlation } \\
\text { Sig. }(2 \text {-tailed) }\end{array}$} & $.862 * *$ & $.850 * *$ & $.848 * *$ & $.861 * *$ & $.850 * *$ \\
\hline & & & 0.006 & 0.008 & 0.008 & 0.006 & 0.008 \\
\hline & \multirow{2}{*}{$\begin{array}{c}\text { Community } \\
\text { Income level }\end{array}$} & \multirow{2}{*}{$\begin{array}{c}\text { Correlation } \\
\text { Sig. (2-tailed) } \\
\end{array}$} & $-.725^{*}$ & -0.694 & -0.681 & -0.697 & $-.708^{*}$ \\
\hline & & & 0.042 & 0.056 & 0.063 & 0.055 & 0.050 \\
\hline \multirow{8}{*}{ 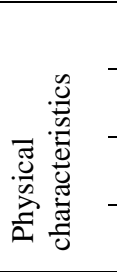 } & \multirow{2}{*}{$\begin{array}{c}\text { Community } \\
\text { area }\end{array}$} & \multirow{2}{*}{$\begin{array}{c}\text { Correlation } \\
\text { Sig. (2-tailed) } \\
\end{array}$} & $.962 * *$ & $.962 * *$ & $.955 * *$ & $.948^{* *}$ & $.958 * *$ \\
\hline & & & 0.005 & 0.018 & 0.020 & 0.006 & 0.010 \\
\hline & \multirow{2}{*}{$\begin{array}{l}\text { Building } \\
\text { area ratio }\end{array}$} & \multirow{2}{*}{$\begin{array}{c}\text { Correlation } \\
\text { Sig. (2-tailed) }\end{array}$} & $.962 * *$ & $.962 * *$ & $.955 * *$ & $948 * *$ & $.958 * *$ \\
\hline & & & 0.005 & 0.018 & 0.020 & 0.006 & 0.010 \\
\hline & \multirow{2}{*}{$\begin{array}{c}\text { Street area } \\
\text { ratio }\end{array}$} & \multirow{2}{*}{$\begin{array}{c}\text { Correlation } \\
\text { Sig. (2-tailed) }\end{array}$} & $-.868^{* *} *$ & $-.797 *$ & $-.788^{*}$ & $-.863 * *$ & $-.836^{* *}$ \\
\hline & & & 0.005 & 0.018 & 0.020 & 0.006 & 0.010 \\
\hline & \multirow{2}{*}{$\begin{array}{c}\text { Garden area } \\
\text { ratio }\end{array}$} & \multirow{2}{*}{$\begin{array}{c}\text { Correlation } \\
\text { Sig. (2-tailed) }\end{array}$} & $-.847 * *$ & $-.821 *$ & $-.771 *$ & $-.790^{*}$ & $-.807 *$ \\
\hline & & & 0.008 & 0.012 & 0.025 & 0.020 & 0.015 \\
\hline \multirow{4}{*}{ 莺 } & \multirow{2}{*}{$\begin{array}{l}\text { Urban space } \\
\text { area/total }\end{array}$} & \multirow{2}{*}{$\begin{array}{l}\text { Correlation } \\
\text { Sig. (2-tailed) }\end{array}$} & -0.847 & -0.821 & -0.771 & -0.79 & -0.807 \\
\hline & & & 0.008 & 0.012 & 0.025 & 0.02 & 0.015 \\
\hline & \multirow{2}{*}{$\begin{array}{l}\text { Urban space } \\
\text { M2/resident }\end{array}$} & \multirow{2}{*}{$\begin{array}{c}\text { Correlation } \\
\text { Sig. (2-tailed) }\end{array}$} & $-.921 * *$ & $-.919 * *$ & $-.867 * *$ & $-.902 * *$ & $-.906 * *$ \\
\hline & & & 0.001 & 0.001 & 0.005 & 0.002 & 0.002 \\
\hline \multirow{4}{*}{ 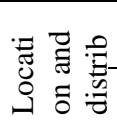 } & \multirow{2}{*}{$\begin{array}{l}\text { Hierarchy of } \\
\text { urban spaces }\end{array}$} & \multirow{2}{*}{$\begin{array}{l}\text { Correlation } \\
\text { Sig. (2-tailed) }\end{array}$} & $-.868 * *$ & $-.856^{* *}$ & $-.806^{*}$ & $-.831 *$ & $-.838 * *$ \\
\hline & & & 0.005 & 0.007 & 0.016 & 0.011 & 0.009 \\
\hline & \multirow{2}{*}{$\begin{array}{l}\text { Public to } \\
\text { private map }\end{array}$} & Correlation & $.969 * *$ & $.955 * *$ & $.948 * *$ & $.944 * *$ & $.950 * *$ \\
\hline & & Sig. (2-tailed) & 0.000 & 0.000 & 0.000 & 0.000 & 0.000 \\
\hline & Physical & Correlation & -0.786 & -0.765 & -0.703 & -0.736 & -0.746 \\
\hline$: \equiv$ & accessibility & Sig. (2-tailed) & 0.021 & 0.027 & 0.052 & 0.037 & 0.034 \\
\hline$\frac{7}{4}$ & Visual & Correlation & $-.868 * *$ & $-.797 *$ & $-.788^{*}$ & $-.863 * *$ & $-.836 * *$ \\
\hline 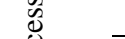 & accessibility & Sig. (2-tailed) & 0.005 & 0.018 & 0.020 & 0.006 & 0.010 \\
\hline 过 & & Correlation & $.946^{* *}$ & $.946^{* *}$ & $.941 * *$ & $.930 * *$ & $.940 * *$ \\
\hline$\ll \lambda$ & Walkability & Sig. (2-tailed) & 0.000 & 0.000 & 0.000 & 0.001 & 0.001 \\
\hline & Diversity of & Correlation & $.934 * *$ & $.852 * *$ & $.851 * *$ & $.880 * *$ & $.885 * *$ \\
\hline Qualit & Activities & Sig. (2-tailed) & 0.001 & 0.007 & 0.007 & 0.004 & 0.004 \\
\hline ative & Quality of & Correlation & $-.784^{*}$ & $-.755^{*}$ & $-.720^{*}$ & $-.726^{*}$ & $-.748^{*}$ \\
\hline & Landscape & Sig. (2-tailed) & 0.021 & 0.030 & 0.044 & 0.041 & 0.033 \\
\hline
\end{tabular}

** Correlation is significant at the 0.01 level (2-tailed). $\quad *$ Correlation is significant at the 0.05 level (2-tailed). (source: author)

Figure (10) illustrate a graphical representation of the deduced correlation coefficients that represent strength and direction of the relationship between urban spaces physical characteristics and social sustainability are deduced. Five factors of neighborhood characteristics have positive impact on social sustainability, walkability, age of community, diversity of activities and community density) that records $0.958,0.94$, $0.902,0.885$, and 0.85 , respectively. Ten factors have negative impacts on achieving social sustainability (quantitative measures $\mathrm{m} 2$ per residents, hierarchy of urban space, streets area, visual and physical accessibility, and garden area per total area) that records $-0.906,-0.838,-0.836$, and -0.807 respectively; and moderate negative impacts on social sustainability as (resident income, community size and quality of landscape design) that records $-0.708,-0.708$, and -0.583 respectively.

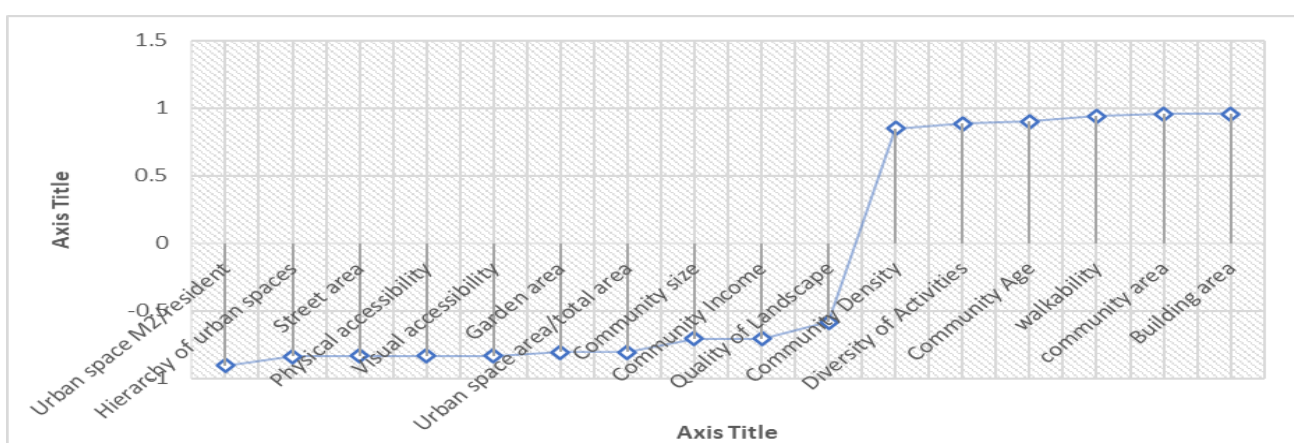

Fig. 10 Graphical representation of correlation between social sustainability and urban space configuration (source: author). 


\subsubsection{Community age and residential socio-economic characteristics}

Community age recorded (0.902) a positive correlation, where residents have more trust and willing to include in urban spaces and engage to their community. On the other hand, Housing income recorded (-0.708) a negative value, where the lower income levels are more willing to include, Interact and participate in urban space. Furthermore, residential density records (0.850) strong positive values, where high density community are more able to encourage residents for inclusion, Interaction, and participation in urban space.

\subsubsection{Quantitative provision of urban spaces (in terms of community area)}

Figure (11) reveals that quantitative provision of urban spaces record (-0.807); which indicate a negative impact on urban social sustainability. This could be due to the impacts of increasing size of urban space on increasing travel distance between residents that requires effort, cost, and time that make residents are not willing to involve, meet or interact in urban spaces.

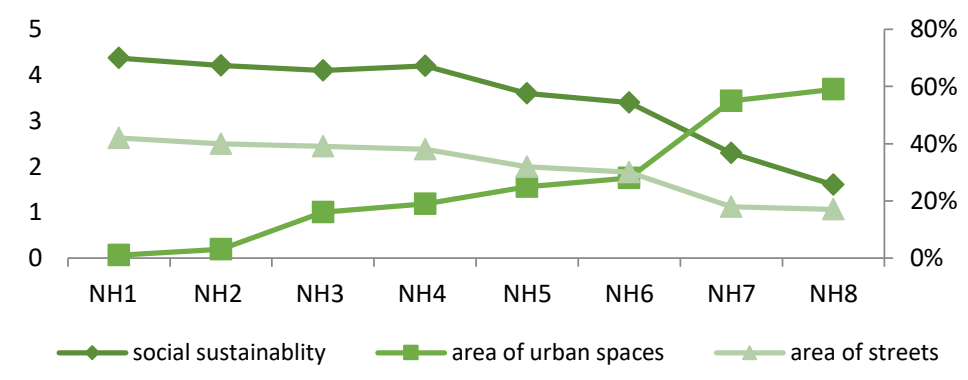

Fig. 11 Relation between urban spaces area and urban social sustainability (source: author).

\subsubsection{Quantitative provision of urban spaces (in terms of community size)}

Figure (12) reveals that quantitative provision of urban spaces (in term of community size) records -0.807 , which indicates that moving from low to higher rate of urban spaces ( $\mathrm{m} 2 /$ resident) reduces social inclusion and interaction. This could be due to the reduced community size in urban spaces that failed to provide sufficient dense concentration of people and could make spaces empty of people and lack surveillance. It also lacks the critical mass of activities to animate public spaces and lacks the efficient and diverse activities that ensure diversity, choices, variety and complexity, and to support more viable range of uses, and activity to animate public spaces.

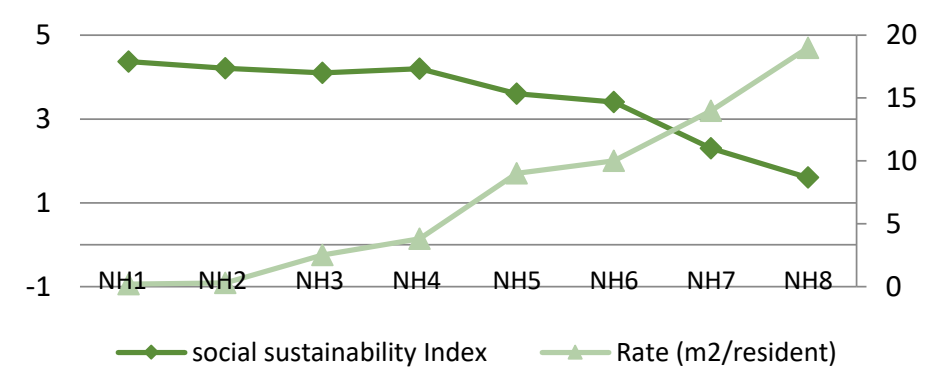

Fig. 12 Relation between urban space m2/resident and urban social sustainability (source: author).

\subsubsection{Location and distribution of urban space}

Figure (13) reveals that central location and hierarchal distribution of urban spaces records (-.838), which indicates that increasing hierarchy of urban spaces reduces urban 
space inclusion of residents and nonresidents. In one hand, hierarchical pattern increases travel distance accordingly increase effort, time, and cost for residents to be included in urban spaces and reduce accessibility for community residents. Reduced accessibility to urban spaces makes it becomes an exclusive destination; a place to go to rather than a place that might pass through. This diminishes by-product of movement or the potentialities of other optional activities in-addition to the basic activity of traveling from point to another. Furthermore, it increases territoriality, responsibility, and control of only the direct surrounding residents to urban spaces and exclude the intrusion of other residents, neighbors, strangers, and adjacent community residents to urban space. It limits pedestrian movement to gardens and exclude pedestrian from streets that makes street unsuitable as social space rather it become a connecting path.

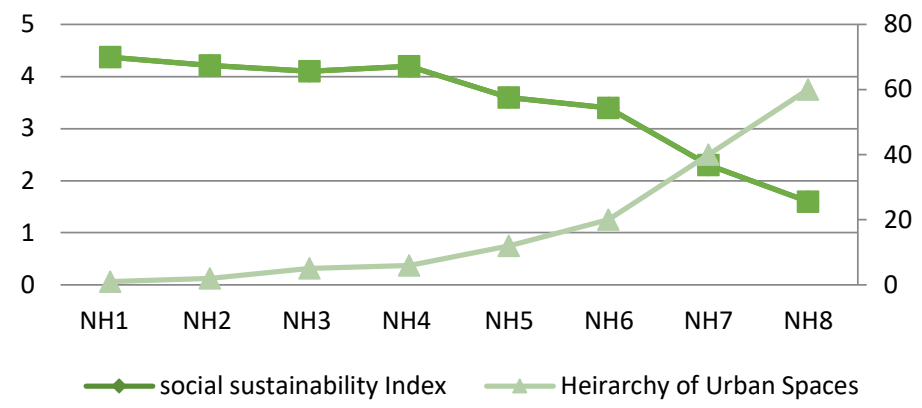

Fig. 13. Relation between urban spaces hierarchy pattern and urban social sustainability(source: author).

\subsubsection{Public to private mapping}

Figure (14) reveals that Public to private mapping records (0.95) this can be explained that the cluster closed pattern surrounding public spaces, limit the periphery of public space, the back yards of ground floor private gardens put high degree of territoriality, privacy, natural surveillance, and control over the attached public space that limit other community residents to define the difference between the public and the private and limit where the public can access, include, move, act, and interact. Residents are not free to move at any time and cannot include in public open space.

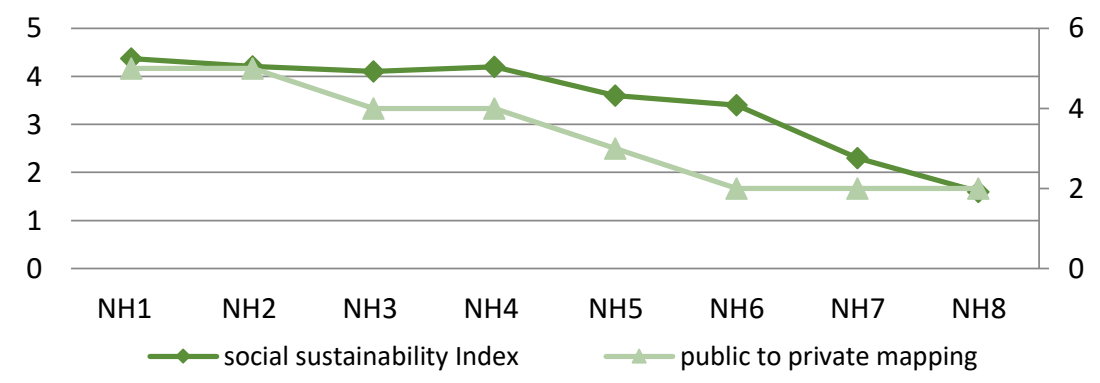

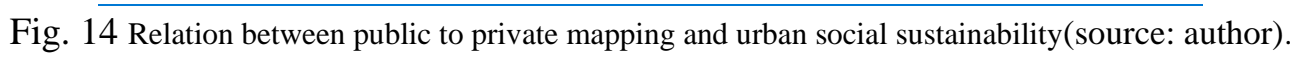

\subsubsection{Accessibility to urban spaces: visual - physical}

Figure (15) reveals that visual and physical accessibility records (-0.746), which indicates that visual and physical accessibility are not necessarily increasing social sustainability. It is a facilitating factor that could increase opportunities for direct inclusion to urban spaces, by eliminating visual and physical barriers of movement by provide clear vision of access point to minimize isolation and increase attractiveness to residents. This give rise to a third type of psychological accessibility, that concerns 
removing the psychological obstacles that limit residents inclusion to urban spaces, and make residents are not willing to involve in urban spaces to avoid cutting the private domain of ground floor residential buildings. Besides, urban space does not encourage pedestrian movement behavior and do not allow for attractive activities that make residents do not have interest to involve in urban spaces.

Contemporary neighborhoods provide hard physical and visual accessibility that expected to increase social inclusion, rather it recorded lower values due to limited psychological accessibility. Traditional neighborhoods provide spatial and visual accessibility where public grid street reduces travel distance and give alternative opportunities that impact resident's movement behavior to public mode choices and encourage walkability and facilitate social inclusion, interaction, and participation as byproduct of movement. On the other hand, it provides what is missing in contemporary neighborhoods which is hard psychological accessibility, private mapping is limited, most of the ground floor plans are public, that encourage resident's involvement.

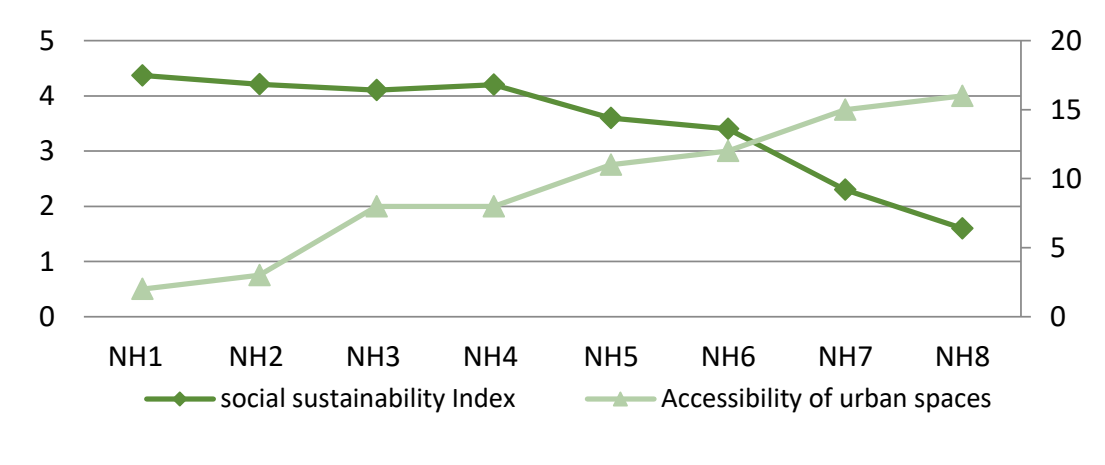

Fig. 15 Relation between urban spaces visual and physical accessibility and urban social sustainability (source: author).

\subsubsection{Circulation pattern}

Figure (16) reveals that walkability records (.940) which indicates that social sustainability is increased with increasing community walkability, where travel distance is reduced to urban spaces enhancing accessibility and accordingly increase social inclusion and interaction between residents. In one hand, hierarchical pattern increases travel distance accordingly increase effort, time, and cost for residents to be included in urban spaces and increase accessibility for community residents. Furthermore, public grid street pattern reduces travel distance and give alternative opportunities that impact resident's movement behavior to walkability and give streets and urban spaces the social inclusion, interaction, and participation as byproduct of movement.

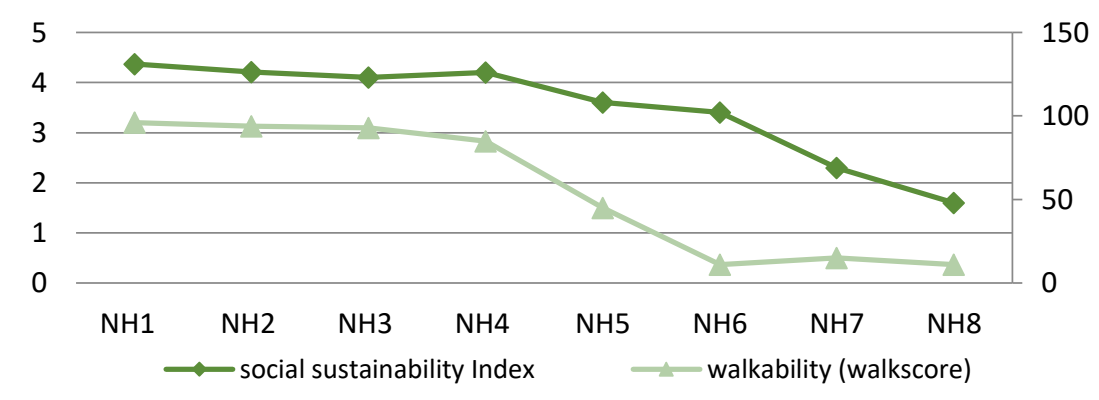

Fig. 16 Relation between urban spaces walkability pattern and urban social sustainability (source: author). 


\subsubsection{Activities inside urban spaces}

Figure (17) reveals that activities inside urban spaces records (0.885) positive relation. which indicates that increasing diversity of activities positively impacts social sustainability. This can be explained as increasing diversity of activities on urban spaces encourage inclusion of diversity of integrators such as residents, passers and targeters. It can increase social inclusion, interaction, and participation to be merged as by product of other social, economic, entertainment attractive activities. Furthermore, resident's inclusion and interaction can be increased in collective activity that gathers mass of people. Urban space in contemporary neighborhoods provides only entertainment and ethical needs as individual activities, which reduce the opportunities of social inclusion. Rather urban spaces in traditional neighborhoods provide a variety of functional, economic, and social activities that are mostly collective activity that increase mass inclusion as by-product of collective activities.

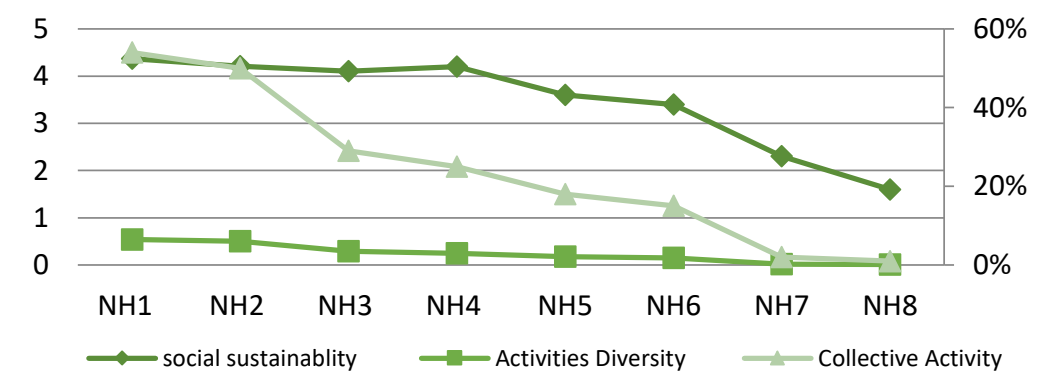

Fig. 17 Relation between urban spaces Activities pattern and urban social sustainability (source: author).

\subsubsection{Well-Designed landscape inside urban spaces}

Figure (18) reveals that well-designed landscape records (-0.748) negative relation. It indicates that providing a well-designed landscape inside urban spaces is not necessarily increase social sustainability. Urban spaces in Contemporary neighborhoods provide high quality landscape design that visually attractive, it has succeeded to achieve a good leisure facility as a marketing tool; Rather it failed to achieve social sustainability.

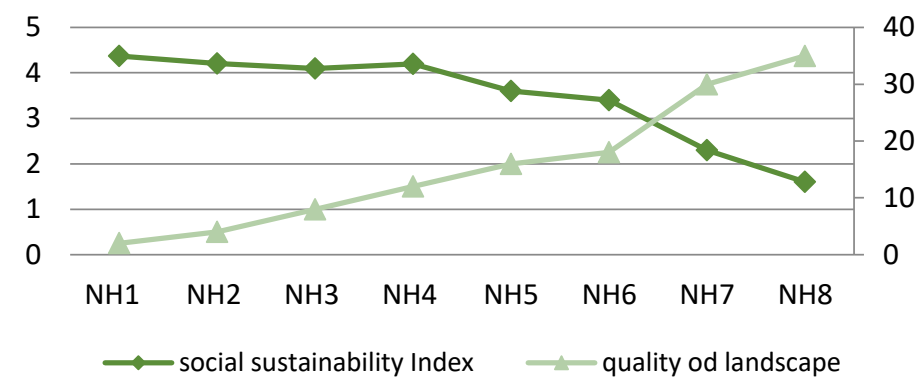

Fig. 18 Relation between urban spaces landscape quality and urban social sustainability (source: author).

\section{CONCLUSIONS AND RECOMMENDATIONS}

The research examines the impacts of urban space configuration on achieving social sustainability, it is concluded that the evolution of urban spaces from traditional to contemporary suburban has negative impacts on urban social sustainability. Revisiting urban space in traditional neighborhoods give lessons that should be learned to pave the way for design guidelines for preparing new plans of new settlements to enhance 
social sustainability of contemporary urban spaces. The research concluded the following:

1- Traditional urban spaces provide lessons that could enhance social sustainability in modern cities. First: Urban spaces should facilitate inclusion of diversity of integrators including community residents, adjacent community residents, passers, and targeters; Urban spaces should facilitate inclusion of diversity of residents in terms of income, age, gender, and physical health; Urban spaces should facilitate all types of social interaction including passive and active interaction, intentional and accidental interaction. Second: Urban spaces should facilitate intended social activities, social activities as byproduct of movement, and social activities as subsidiary of another attractive activities. Third: Urban spaces should facilitate public and pedestrian movement behavior that gather people and increase social activity as byproduct of movement. Finally: Urban spaces should provide variety of collective activities that gather more peoples, and variety of types of activities that meet economic, cultural, social, and political activities, and increase social activity as subsidiary of another attractive activities.

2- Urban spaces in contemporary planned neighborhoods depends on high qualitative provision of urban spaces, merged and integrated urban spaces location and hierarchical distribution, hard visual and physical accessibility to urban spaces, and well designed and maintained landscaping; rather it stands short against achieving intended social inclusion, social inclusion as subsidiary of diversity of activities, and social inclusion as byproduct of movement; it failed to achieve intentional and accidental interaction; it failed to achieve social participation. On the other hand, urban spaces in traditional neighborhoods with limited provision of urban spaces and low quality of landscape, rather it records higher urban social sustainability based on three reasons the high residential density that encourage intended and nonintended inclusion, the high diversity of non-residential activities that encourage social inclusion, interaction and participation as subsidiary activity, and will connected high walkability that encourage social inclusion and interaction as byproduct activity of movement.

3- Minimizing social inclusion in urban spaces as intended behavior is short sighted; rather social inclusion has three reasons: Social inclusion as intended activity, Social inclusion as by product of movement behavior, and Social inclusion as subsidiary social activity for another attractive activities. And those residents will hardly pay effort, time, and cost to act social inclusion as intended activity. To increase the probabilities of social inclusion, interaction, and participation; planners need to extend social inclusion to meet the three reasons of inclusion. That is why traditional urban spaces provide lessons that should be learned to enhance urban social sustainability in contemporary urban spaces.

4- Minimizing the scope of urban space guidelines in quantitative provision of urban spaces, good accessibility and well-designed landscape is short sighted vision; rather the scope should extend to qualitative guidelines with providing mixed activities and high density are the most influential factor that encourage social interaction as byproduct of movement and as subsidiary activity to attractive activities. It can bring people to gather and encourage collective social, economic, and cultural interaction. 
5- In order to develop design guidelines to enhance urban social sustainability, regulations should depend on three main pillars:

(a) Provision indicators are responsible to provide required area of urban spaces for interaction and to provide the required dense concentration of people to animate urban spaces. Quantitative provision of urban spaces does not necessarily limit or encourage social sustainability, rather increasing urban spaces area could reduce social interaction if it increases time and effort residents consume to gather in urban space to practice interaction as separate activity.

(b) Facilitating indicators are responsible for removing any obstacles that might face resident's invitation to urban spaces, starting from removing physical and visual obstacles of movement, to reducing travel distance, cost, and effort. It works as a facilitating factor for enhancing social inclusion and interaction. Its effectiveness is depending on its impacts on facilitating movement behavior and encouraging walkability and public modes choices that attracts people to act social behavior as byproduct of movement.

(c) Qualitative provision indicators which are attracting indicators. They are the most influential factors for fostering people to gather in urban spaces. It concerns increasing the dense concentration of integrators in urban spaces to provide the critical mass of activities and provide efficient and diverse activities to animate urban spaces. It concerns provision of mixed uses that provide different nonsocial activities that give the opportunities for social interaction to occur as byproduct. It concerns to provide safety and security and attract people to act social behavior as subsidiary to another attractive activity as in table 9 .

Table 9. Classification of the impacts of urban space configuration on type of social behavior.

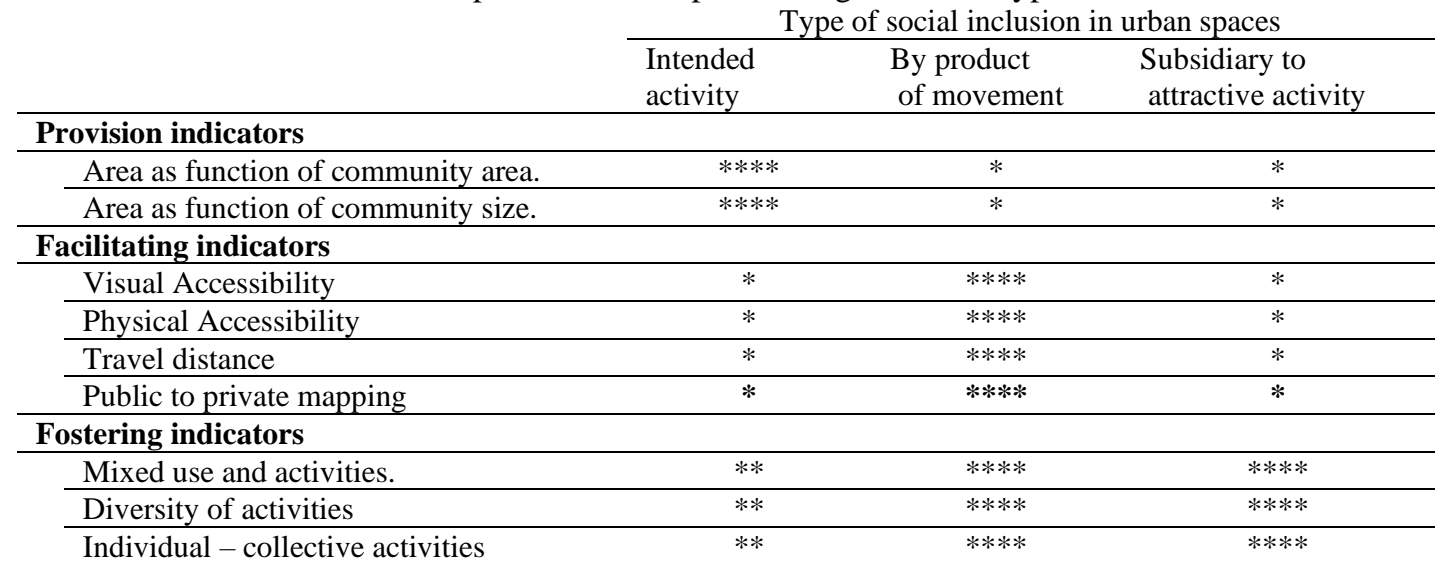

(source: author)

\section{REFERENCES}

Adham, K. (2005). Globalization, Neoliberalism, and New Spaces of Capital in Cairo. Traditional Dwellings and Settlements Review, 17(1), 19-32. Retrieved December 29, 2020, from http://www.jstor.org/stable/41758302

Agyeman, J. (2005). Sustainable communities and the challenge of environmental justice. NYU Press. Allocated, L., \& Core, C. (2013). Streets as public spaces and drivers of urban prosperity. Of urban prosperity, 108.

Abu-Lughod, J. (1971). Cairo: 1001 Years of the City Victorious. PRINCETON, NEW JERSEY: Princeton University Press. doi:10.2307/j.ctv7n0cmg

Bahamam, A. S. (2001). Applying Urban Design to Prevent Crime in Residential Areas A Case Study of the Contemporary Neighborhoods in Riyadh. Journal of science, medicine, and engineering Om El Kora University, Mecca, KSA. https://fac.ksu.edu.sa/sites/default/files/140_1.pdf. 
Bartlett School of Architecture, Planning UCL (2004). Living Places: caring for quality. London: RIBA, 2004.

Berube, A. (2005) "Mixed communities in England: A US perspective on evidence and policy prospects" Joseph Rowntree Foundation

Bramley, G., Dempsey, N., Power, S., Brown, C., \& Watkins, D. (2009). Social sustainability and urban form: evidence from five British cities. Environment and planning A, 41(9), 2125-2142.

Chan, E., \& Lee, G. K. (2008). Critical factors for improving social sustainability of urban renewal projects. Social Indicators Research, 85(2), 243-256.

Chitrakar, R. M., Baker, D. C., \& Guaralda, M. (2017). Changing provision and use of neighbourhood public space in Nepal's Kathmandu Valley. Journal of Architecture and Urbanism, 41(1), 46-59.

Chitrakar, R. M., Baker, D., \& Guaralda, M. (2014). Urban growth in the Kathmandu Valley: The transformation of public space. Past Present and Future of Public Space - International Conference on Art, Architecture and Urban Design Bologna (Italy), June 25 - 27, 2014.

Chiu, R. L. (2003). 12 Social sustainability, sustainable development, and housing development. In Forrest, R., \& Lee, J. (Eds.). (2003). Housing and social change: East-West perspectives. Routledge.

Colantonio, A., Dixon, T., Ganser, R., Carpenter, J., \& Ngombe, A. (2009). Measuring Socially Sustainable Urban Regeneration in Europe.

Cuthill, M. (2010). Strengthening the 'social'in sustainable development: Developing a conceptual framework for social sustainability in a rapid urban growth region in Australia. Sustainable development, 18(6), 362-373.

Dave, S. (2011). Neighbourhood density and social sustainability in cities of developing countries. Sustainable Development, 19(3), 189-205.

Dempsey, N. (2008). Does quality of the built environment affect social cohesion? Proceedings of the Institution of Civil Engineers-Urban Design and Planning, 161(3), 105-114.

Dempsey, N., Bramley, G., Power, S., \& Brown, C. (2011). The social dimension of sustainable development: Defining urban social sustainability. Sustainable development, 19(5), 289-300.

Denis, E. (2006). Cairo as neoliberal capital? From Walled City to Gated Community, in D. Singerman and P. Amar (Eds), Cairo Cosmopolitan, AUC Press.

Great Britain. Department for Transport, Local Government and the Regions. (2002). Green Spaces, Better Places: Final Report of the Urban Green Spaces Taskforce. DTLR, London, 2002.

El-Husseiny, M. A. (2013). Role of public space in achieving social sustainability in Cairo. Asian Journal of Environment-Behaviour Studies, 4(14), 145-158.

Farhadikhah, H., \& Ziari, K. (2020). Social sustainability between old and new neighborhoods (case study: Tehran neighborhoods). Environment, Development and Sustainability, 1-18.

Forrest, R., \& Kearns, A. (2001). Social cohesion, social capital, and the neighborhood. Urban studies, 38(12), 2125-2143.

Gehl, J. (2011). Life between buildings: using public space. Island press.

Ghonimi I., (2014) "The Evolution of Neighborhood Models as A Manifestation of Political Regime Shift: A case Study of Cairo - Egypt". Our Common Future in urban morphology: 21st International Seminar on Urban Form FEUP, Porto ISUF 2014.

Ghonimi, I. \& Shahata, I. (2017). Measuring the correlation between neighborhood models and crime rates and sense of security. A case study of four neighborhoods adjacent to criminal focal points in $\begin{array}{llll}\text { Cairo-Egypt. Journal of } \quad \text { Urban } & \text { Research, 23(1), }\end{array}$ https://dx.doi.org/10.21608/jur.2017.89109.

Ghonimi, I. (2018) "Socially sustainable neighborhood in Egypt: Assessing Social Capital for Different Neighborhood Models in Greater Cairo Region.” Journal of Engineering Sciences Assiut University, vol.46.

Ghonimi, I., \& El Zamly, H. (2017, September). Sustainable Urban Mobility: Assessing Different Neighbourhood Models in Greater Cairo Region, Egypt. In REAL CORP 2017-PANTA RHEI-A World in Constant Motion. Proceedings of 22nd International Conference on Urban Planning, Regional Development and Information Society (pp. 561-575). 
Grogan-Kaylor, A., Woolley, M., Mowbray, C., Reischl, T. M., Gilster, M., Karb, R., ... \& Alaimo, K. (2006). Predictors of neighborhood satisfaction. Journal of Community Practice, 14(4), 27-50.

Hagen, B., Nassar, C., \& Pijawka, D. (2017). The social dimension of sustainable neighborhood design: comparing two neighborhoods in Freiburg, Germany. Urban Planning, 2(4), 64-80.

Harvey, D. (1996). "Justice, Nature and the Geography of Difference" Blackwell Publishers.

Ibrahim, A., \& Alattar, A. (2017). Street networks between traditional and new Egyptian developments, problems and learned lessons. Procedia Environmental Sciences, 37, 306-318.

Kamon, H. (1997). The relationship between urbanization and criminology), El Maousoa Journal (405).

Karuppannan, S., \& Sivam, A. (2011). Social sustainability and neighbourhood design: an investigation of residents' satisfaction in Delhi. Local Environment, 16(9), 849-870.

Kearns, A., \& Forrest, R. (2000). Social cohesion and multilevel urban governance. Urban studies, 37(56), 995-1017.

Larimian, T., \& Sadeghi, A. (2019). Measuring urban social sustainability: Scale development and validation. Environment and Planning B: Urban Analytics and City Science, https://doi.org/10.1177/2399808319882950.

Leyden, K. M. (2003). Social capital and the built environment: the importance of walkable neighborhoods. American journal of public health, 93(9), 1546-1551.

Lovejoy, K., Handy, S., \& Mokhtarian, P. (2010). Neighborhood satisfaction in suburban versus traditional environments: An evaluation of contributing characteristics in eight California neighborhoods. Landscape and urban planning, 97(1), 37-48.

Mboup, G. (2015). Streets as public spaces and drivers of sustainable, inclusive and prosperous cities in Africa, 2015. In World Bank Land and Poverty Conference, Washington, D.C. https://mirror.unhabitat.org/pmss/listItemDetails.aspx?publicationID=3513

Mboup, G. (2013). Streets as public spaces and drivers of urban prosperity. United Nations Human Settlements Programme (UN-Habitat).

Mitchell, L, Burton, E (2006) 'Neighbourhoods for Life: Designing Dementia-Friendly Outdoor Environments', Quality in Ageing and Older Adults 7(1): 26-33. https://doi.org/10.1108/14717794200600005

Neilagh, Z. M., \& Ghafourian, M. (2018). Evaluation of social sustainability in residential neighborhoods. European Journal of Sustainable Development, 7(1), 209-209.

Newman, O. (1996). Creating defensible space. Diane Publishing.

The National Organization for Urban Harmony. (2010). Heuristic guide of Principles and Standards of Urban Harmony for Advertisement and Signboards. Supreme council for planning and urban development. Retrieved from http://www.urbanharmony.org/en/images/T.O.R_Eng.pdf

Putnam robert, Robert (2000) Bowling Alone: The Collapse and Revival of American Community (New York: Simon and Schuster).

Rao, P. (2018). Assessment of Usability of Green Spaces for Low and Higher mobility User in Gated Residential Communities through Accessibility Indicator. International Journal of Applied Engineering Research, 13(13), 11172-11182.

Sachs, I. (1999), "Social sustainability and whole development: exploring the dimensions of sustainable development”. In: B. Egon and J. Thomas, (Eds.), Sustainability and the social sciences: a crossdisciplinary approach to integrating environmental considerations into theoretical reorientation, Zed Books.

Shalaby, A.-F.S. (2003) Transfer of Ideas through Planning Education in Egypt: The Case of the Spatial Form of Low-Income Housing. PhD dissertation, Cardiff University, Cardiff

Shirazi, M. R., \& Keivani, R. (2019). Social sustainability discourse: a critical revisit. In Shirazi, M. R., \& Keivani (Eds.), Urban Social Sustainability (pp. 1-26). Routledge.

Southworth, M., \& Ben-Joseph, E. (2013). Streets and the Shaping of Towns and Cities. Island Press.

Tsenkova, S. (2009) "Planning Sustainable Communities Diversity of Approaches and Implementation Challenges", University of Calgary. 